\title{
Development of the Korean Practice Parameter for Adult Attention-Deficit/Hyperactivity Disorder
}

\author{
Geon Ho Bahn ${ }^{1 \star}$, Young Sik Lee ${ }^{2 \star}$, Hanik K. Yoo ${ }^{3}$, Eui-Jung Kim ${ }^{4}$, Subin Park ${ }^{5}$, \\ Doug Hyun $\mathrm{Han}^{2}$, Minha Hong ${ }^{6}$, Bongseog $\mathrm{Kim}^{7}$, Soyoung Irene $\mathrm{Lee}^{8}$, \\ Soo Young Bhang ${ }^{9}$, Seung Yup Lee', Jin Pyo Hong ${ }^{10}$, and Yoo-Sook Joung ${ }^{10}$ \\ ${ }^{1}$ Department of Psychiatry, Kyung Hee University School of Medicine, Seoul, Korea \\ ${ }^{2}$ Department of Psychiatry, Chung-Ang University Hospital, Chung-Ang University College of Medicine, Seoul, Korea \\ ${ }^{3}$ Seoul Brain Research Institute, Seoul, Korea \\ ${ }^{4}$ Department of Psychiatry, College of Medicine, Ewha Womans University, Seoul, Korea \\ ${ }^{5}$ Department of Research Planning, Mental Health Research Institute, National Center for Mental Health, Seoul, Korea \\ ${ }^{6}$ Department of Psychiatry, Myongji Hospital, Hanyang University College of Medicine, Seoul, Korea \\ ${ }^{7}$ Department of Psychiatry, Inje University College of Medicine, Seoul, Korea \\ ${ }^{8}$ Department of Psychiatry, Soonchunhyang University Bucheon Hospital, Soonchunhyang University College of Medicine, Buchun, Korea \\ ${ }^{9}$ Department of Psychiatry, Eulji University School of Medicine, Seoul, Korea \\ ${ }^{10}$ Department of Psychiatry, Samsung Medical Center, Sungkyunkwan University School of Medicine, Seoul, Korea
}

Objectives: Adult attention-deficit/hyperactivity disorder (ADHD) is an important mental health problem that needs resolution, especially considering the high rates of ADHD continuation from childhood to adolescence/adulthood and the high prevalence of ADHD in adults. Adults with ADHD have lifelong negative impacts and require close monitoring with long-term follow-up. Hence, the establishment of a Korean practice parameter for adult ADHD is necessary to minimize discontinuation of treatment and enable information sharing among Korean mental health professionals.

Methods: The Korean practice parameter was developed using an evidence-based approach consisting of expert consensus survey coupled with literature review.

Results: According to the expert consensus survey, the most commonly used diagnostic methods were clinical psychiatric interview (20.66\%) and self-report scales (19.25\%) followed by attention (14.71\%) and psychological tests (14.24\%). Key evaluation instruments currently available in Korea are the World Health Organization Adult ADHD Self-Report Rating Scale, Korean Adult ADHD Rating Scale, Diagnostic Interview for ADHD in Adults, Barkley Deficits in Executive Functioning Scale for adults, Comprehensive Attention Test, Conners' Continuous Performance Test, and the subtests of Wechsler Adult Intelligence Scale, Digit Span and Letter-Number Sequencing. Although pharmacotherapy is recommended as the first-line of treatment for adult ADHD, we recommend that it be followed by a multimodal and multidisciplinary approach including psychoeducation, pharmacotherapy, cognitive behavior therapy and coaching. Conclusion: The Korean practice parameter introduces not only general information for the diagnosis and treatment of adult ADHD on a global scale, but also the process of diagnosis and treatment options tailored to the Korean population.

Key Words: Practice parameter; Korean; Adult; Attention-deficit/hyperactivity disorder; Evaluation; Treatment.

Received: August 26, 2019 / Revision: September 18, 2019 / Accepted: September 19, 2019

Address for correspondence: Yoo-Sook Joung, Department of Psychiatry, Samsung Medical Center, Sungkyunkwan University School of Medicine, 81 Irwon-ro, Gangnam-gu, Seoul 06351, Korea

Tel: +82-2-3410-3589, Fax: +82-2-3410-0550, E-mail: yschoung@skku.edu

*These authors contributed equally to this work.

\section{INTRODUCTION}

There is currently a severe lack of clinical interest and research in adult attention-deficit/hyperactivity disorder (ADHD) amongst mental health professionals in Korea. This has been exacerbated by a practice of Korean health insurance provid-

This is an Open Access article distributed under the terms of the Creative Commons Attribution Non-Commercial License (https://creativecommons.org/licenses/by-nc/4.0) which permits unrestricted non-commercial use, distribution, and reproduction in any medium, provided the original work is properly cited. ers, where benefits cannot be availed for ADHD medications when a patient is first diagnosed with ADHD in adulthood and not in childhood/adolescence. However, this problem has since been rectified with the provision of insurance benefits for these patients from September 2016 [1]. Hence, there is now an urgent need for a practice parameter that complies with available assessment tools and promotes suitable diagnostic processes or therapeutic interventions that can be shared amongst health professionals. 
According to the current clinical practice in Korea, patients diagnosed with ADHD in childhood/adolescence can continue regular treatment in adulthood. General practitioners treat many adult ADHD patients who stopped treatment after initial diagnosis in childhood/adolescence and resumed it later during adulthood. They also treat patients who did not receive appropriate intervention when required and desire treatment in adulthood. Unfortunately, in many cases the treatment is targeted towards episodic symptoms, resulting in premature discontinuation of treatment in $\mathrm{ADHD}$ cases that require close monitoring and long-term follow-up. In order to avoid such discontinuation and facilitate dialogues between mental health professionals, a Korean practice parameter for adult ADHD is necessary.

A recent preliminary survey that used the Adult ADHD SelfReport Scale (ASRS) [2] to screen patients who visited the Department of Psychiatry for emotional symptoms reported that $55.7 \%$ of the respondents showed signs of adult ADHD [3]. As such, patients who visit the Psychiatric Outpatient Clinic are more likely to show a higher prevalence of adult ADHD than those who do not. Therefore, it becomes vital to screen for ADHD in adults who voluntarily seek psychiatric aid. A standardized approach is hence required to diagnose patients who have completed screening for adult ADHD, and consensus among mental health professionals is needed regarding the interventions be implemented thereafter.

The Adult ADHD Special Interest Study Group, a subdivision of the Korean Academy of Child and Adolescent Psychiatry (KACAP-AASIG) conducted studies aiming to standardize adult ADHD assessment tools, such as a Korean version of the World Health Organization (WHO) ASRS, an ASRS screener [2], a Korean Adult ADHD Rating Scale (K-AARS) [4], and a Diagnostic Interview for ADHD in Adults-5 (DIVA-5) [5]. Although preliminary data were published regarding a practice parameter for adult ADHD [6], we aimed to further fine tune this for Korean adults with ADHD and establish a standard practice that mental health professionals can refer to during diagnosis.

The scope and purpose of this practice parameter are as follows:

1) Target patients who voluntarily seek psychiatric help.

2) Improve public health in terms of adult ADHD screening, diagnosis, and treatment.

3) Implement a basic framework for clinical practice of adult ADHD patients and disseminate it to mental health specialists.

The experts involved in the development of this practice parameter are psychiatric specialists. The practice parameter was developed using an evidence-based approach consisting of an expert consensus survey and a literature review. Given that adult ADHD has only been recently introduced as a general psychiatric disorder in Korea, we surveyed psychiatric professionals regarding the clinical status of adult ADHD. Databases for the literature review include MEDLINE and KoreaMed. Other sources of literature review were book chapters, previously published guidelines and those provided by colleagues. The literature scans were conducted from January 2018 through February 2019 using the key words "attentiondeficit hyperactivity disorder" and "adult," with patient age limited to 19 years and above. The search period ranged from 2010 to 2019 and yielded about 4800 references. When the article type was further whittled down to randomized controlled trials, systemic reviews and guidelines, 440 references remained. Of these articles, the titles and abstracts were reviewed and we selected those from the relevant field based on etiology, evaluation, diagnosis, and treatment of ADHD.

\section{BACKGROUND}

\section{Etiology of ADHD in adults}

The etiology of ADHD is complex and includes both genetic and environmental factors. However, several studies suggest that the causes of ADHD are largely genetic and the disorder has high heritability [7].

\section{Genetic factors}

Several studies have shown that ADHD has a strong genetic influence and is inherited across generations [8-11]. Extensive reports from twin and adoption studies have consistently shown high heritability of approximately $75 \%$ for childhood ADHD [12], countering the initial estimates of 30-50\% [13-15]. These differences might be due to rater effects, which when controlled for, reduced the incompatibility between childhood and adult ADHD [16].

\section{Genetic linkage analysis}

Genetic linkage analysis is especially useful for identifying genetic risk factors with large effect sizes in families with ADHD. Chromosome 16q has been reported to be of significance in this regard [17], but further investigations for candidate genes contributing to the ADHD phenotype are required.

\section{Candidate gene association studies}

Candidate gene association studies focus on associations between variation within pre-specified genes of interest and defined phenotypes. The genes are selected for study based on a priori knowledge of their functional impacts on the trait or disease in question [18]. Genes encoding proteins involved in the serotonergic and dopaminergic systems have been associated with $\mathrm{ADHD}$, such as the serotonin transporter 5-hy- 
droxytryptamine transporter (5HTT) and tryptophan hydroxylases (TPH1 and TPH2) [19], and dopamine active transporter (DAT1), and dopamine receptors (DRD4 and DRD5) [20-24]. Such studies are useful in investigating genetic contributions, but may be prone to selection bias due to hypothesis driven analyses [18].

\section{Genome-wide association studies}

Genome-wide association studies (GWAS) scan entire genome for common genetic variations. Several studies have identified the involvement of ADHD-related genes, such as PARK2, SLC6A3, DRD4, DRD5, SLC6A4, HTR1B, SNAP25, DIRAS2, LPHN3, and NOS1 [25-28]. Furthermore GRM5, coding for glutamate receptor $\mathrm{CDH} 13$, and $A D G R L 3$, encoding latrophilin 3 , have also been reported as promising predictors of ADHD risk [29,30]. Given the lack of replicability of these results, however, further studies remain wanting.

\section{Rare genetic variants}

Recently, rare genetic variants have received great attention due to an increase of identified overall rare copy number variants in adults with ADHD [31-33]. In light of the debate regarding the very existence of adult onset ADHD, further studies need to be conducted on whether different genetic factors are at play during childhood and adulthood. Separate genetic research in children and adults with ADHD will help resolve this issue.

\section{Neurochemical factors}

Dopamine and the prefrontal cortex (PFC) have been major foci of clinical investigations on ADHD [34]. Norepinephrine is also known to play a major role in attention. A clear role for dopamine and norepinephrine has been suggested by the positive response of ADHD patients to stimulants (dopamine reuptake inhibitors) and atomoxetine (ATX; norepinephrine reuptake inhibitors) [35].

\section{Neuroanatomical factors}

Structural and functional neuroimaging studies have documented impairments in neural networks associated with executive functioning in both children and adults with ADHD [36]. Abnormal anatomy and dysfunction of inferior frontal and dorsolateral PFC, fronto-striatal and mesocorticolimbic networks, anterior cingulate, parieto-temporal, and cerebellar regions have been secifically highlighted in this regard [37,38]. More recently, the PFC, caudate, and cerebellum have emerged as primary areas showing deficits in ADHD. These areas are interconnected by a network of neurons and together regulate attention, thoughts, emotions, behavior, and actions. Studies in ADHD patients have shown slower maturation of PFC or a smaller volume and reduced activity of the PFC, caudate, and/or cerebellum [39-41]. The most recent brain imaging study showed structural alterations of the lower cortical surface area (mainly frontal, cingulate, temporal pole, and total regions) in children with ADHD when compared with controls. However, these differences were not found in adolescents or adults with ADHD [42]. Studies of adult ADHD patients using positron-emission tomography (PET) have found reductions in glucose metabolism in the premotor and superior PFCs [43]. Another study of adult ADHD patients using PET showed significantly increased DAT binding in the right caudate [44].

\section{Environmental risk factors}

A number of environmental factors for ADHD have been established, such as perinatal stress, low birth weight, traumatic brain injury, and substance abuse, including maternal smoking and alcohol intake [45]. Toxins like lead are also known to contribute to increased risk of ADHD [46,47]. Although weak, there is some evidence for the contribution of psychosocial factors to ADHD development [48].

\section{Trajectories of ADHD from childhood to late adulthood}

The diagnosis of ADHD in adult mandates a detailed developmental childhood history, much more so than other adult psychiatric disorders like schizophrenia and depression. However, such information is not easily accessible as, even though ADHD symptoms in children may begin very early, most parents tend to dismiss them as characteristics of energetic children. Moreover, even if parents recognize the possibility of ADHD, they are reluctant to visit a hospital due to the social stigma of mental illness. Unfortunately, deferring appropriate therapeutic intervention can lead to severe impairment in social adjustment as an adult. Therefore, insight into the developmental trajectory of ADHD is required to minimize misunderstandings and prejudices and also to accurately diagnose and treat $\mathrm{ADHD}$ in adults.

\section{Developmental trajectory of ADHD}

Preschool children, with or without ADHD, can often be excessively active, impulsive, aggressive, and accident prone. These characteristics prompted the change in the cut-off age of ADHD onset from 7 years in the Diagnostic and Statistical Manual of Mental Disorders IV (DSM-IV) [49] to 12 years in the DSM-5 [50]. The higher rate of successful diagnoses in boys is often explained by the fact that they are more likely than girls to exhibit externalizing behaviors. During elementary school, children with ADHD struggle with hyperactivity-impulsivity and attention problems. As compared to their 
peers, children with ADHD exhibit poor school performance in terms of grades, organizing skills, and tasks that require fine motor skills [51]. Adolescents with ADHD often face difficulties in both school and at home owing to inattention and impulsivity. They are also more likely to exhibit antisocial behaviors such as stealing, lying, physical or sexual assaults, and substance abuse. Adults with ADHD tend to prefer more manual labor positions due to curtailed academic careers and have a higher risk of marital discord, substance abuse, and criminal record than individuals without ADHD [52].

ADHD symptoms that develop during childhood continue throughout adolescence and into adulthood. The nature of the symptoms, however, changes. For example, hyperkinetic activity decreases while inattention related symptoms increases as the individual progresses towards adulthood [53]. Interestingly, some research findings have shown that a lack of change in ADHD symptoms over time may in fact have a negative impact on the individual [54]. Considering the lifelong presence and impact of ADHD, not only mental health professionals in child and adult psychiatry, but those in geriatric psychiatry as well would require training in the assessment and treatment of ADHD [55].

The mortality rate related to ADHD is a more recent academic interest. In a Danish national cohort study [56], the mortality rate ratio in individuals with ADHD was significantly increased when compared to that of the general population. This effect was more prominent in females than in males. The raised mortality in ADHD patients appear to be mainly due to deaths by unnatural causes, especially accidents. This hypothesis was also supported by some analysis linked to $\mathrm{Na}-$ tional Health Index in the USA [57]. Contrary to these findings, a Swedish cohort study (total number of samples 1599, mean age over 70 years) using the Wender Utah Rating Scale (WURS), reported that there was no substantially elevated mortality risk in individuals who retrospectively scored higher than WURS cut-off score for ADHD diagnosis [58]. Mortality in ADHD patients is also linked to suicidal behavior [59]. While it remains unclear whether there is a direct relationship between the suicide and ADHD in adults, ADHD symptom severity has been associated with an increased risk for suicidal behavior [60].

Controversies regarding the developmental trajectory of ADHD

Differentiation due to ADHD courses, phenotypes, or biotypes Although ADHD is known to be a persistent and trans-situational pattern that is detrimental to developmental stage and interferes with normal functioning [50], the prevalence rates of diagnosis decline from $5.3 \%$ in childhood [61] to be- tween $1.4 \%$ and 3.6\% in adulthood [62]. The different frequencies of ADHD diagnosis in childhood and adulthood can be explained by a few factors: first, the possibility of natural healing; second, the disorder has been treated and cured during childhood/adolescence; third, the symptoms are masked due to partial remission; fourth, the possibility of concealment behind coexisting mental disorders or transformation of ADHD into a different mental disorder such as symptomatic depression with underlying ADHD (Fig. 1) [52]. According to the Korean Health Insurance Review and Assessment claims database, ADHD is the most common mental disorder in children but the diagnosis rates decrease steeply with age, whereas the diagnosis rates of depression and anxiety increase in adolescence [63]. Similar rates are also seen in female adolescents. The decrease in ADHD prevalence with age may either reflect the natural course of the disorder or the progression of emotional instability, a core ADHD characteristic, to depression or anxiety disorder. It also remains to be investigated whether this change in diagnosis rates is a universal characteristic of ADHD or if it depends on a specific subtype or phenotype.

\section{Late-diagnosed vs. late-identified vs. late-onset $A D H D$}

When diagnosing adult ADHD, it is important to distinguish late-onset $\mathrm{ADHD}$ from any other mental disorder that has been misdiagnosed as ADHD [64]. Moffitt et al. [64] and Agnew-Blais et al. [65] observed the Dunedin birth cohort and England and Wales twin birth cohorts, respectively, and reported late-onset ADHD without any childhood history. Cooper et al. [66] also reported adult onset ADHD with normal childhood development from a UK birth cohort, which ignited the possibility of a previously unidentified form of $\mathrm{ADHD}$ that arises entirely during adulthood. However, there

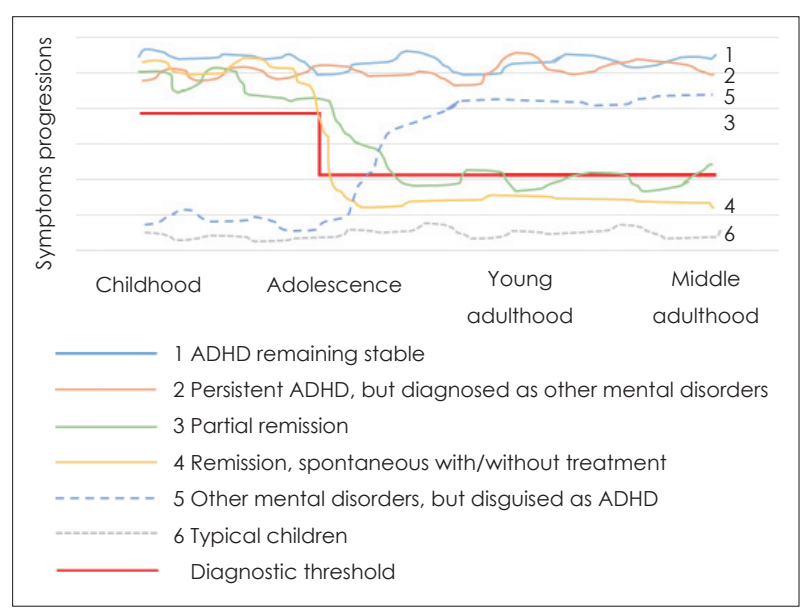

Fig. 1. Trajectories of ADHD and psychiatric comorbidity across the lifespan (modified from Franke B et al. Eur Neuropsychopharmacol 2018;28:1059-1088 [52]). 
are some caveats to these studies, such as the possibility of biased retrospective recall by the parents for the four-decadelong longitudinal cohort study conducted in Dunedin, New Zealand [64]. The parents of 78\% of the participants with childhood ADHD had forgotten the age of ADHD onset before age 12, despite having reported the symptoms at ages 5, 7, 9, and 11 years, and the parents of 35 comparison subjects (4\%) falsely recalled their child as having ADHD.

\section{Possible factors influencing ADHD trajectory}

Proper assessment of ADHD requires documentation from early childhood to old age. The course of ADHD can be affected by many variables, especially environmental and cultural background. In such scenarios, finding consistent prognostic factors remain a challenge. Childhood IQ has been shown to predict better outcomes in several domains [67]. For instance, adults with high intelligence and few psychiatric comorbidities who are diagnosed with ADHD at later stages may have good social lives, despite having ADHD symptoms during childhood [68]. Considering the difficulties of long-term follow-up of individuals with ADHD, thorough reviews of biographies of well-known people allow us to analyze its influence on their life trajectories. Analysis of the biographies of Ernesto Che Guevara by Teive et al. [69] suggests that 'Che' may have had ADHD. Fitzgerald [70] has reviewed and suggested that novelty seekers like, John Lennon, Ulysses Grant, Jule Verne, Sir Walter Raleigh, and Peggy Guggenheim also had ADHD and shared some features of Asperger's syndrome.

\section{Summary of developmental trajectory of ADHD}

Since ADHD can begin during childhood and last a lifetime, a lack of early diagnosis and intervention subjects people to various adverse conditions and poor quality of life. Therefore, insight into the precise developmental trajectory of individuals with ADHD can inform the development of diagnostic criteria, evaluation of prognostic factors and prediction of treatment responses. This makes the meticulous collection and organization of clinical data from developmental trajectory imperative.

\section{CLINICAL PICTURES OF ADHD IN ADULTS}

\section{Prevalence of ADHD}

$\mathrm{ADHD}$ is characterized by persistent and pervasive symptoms of inattention, hyperactivity and impulsivity, which impair the functional capabilities of an individual [50]. The DSM criteria, the most widely used criteria for ADHD diagnosis, categorizes three clinical presentations of ADHD based on heterogeneity in its symptomatic presentations: predominantly inattentive, predominantly hyperactive/impulsive, and com- bined type [50]. Since ADHD usually begins in childhood and is the one of the most common psychiatric disorders during this period, it has been recognized as a condition typical of the pediatric population and which gets better with age. Unfortunately, this means that its prevalence in the adult population has been severely underrated [71].

A growing number of studies suggest that a significant proportion of ADHD symptoms which begin in childhood persist into adulthood. Longitudinal studies indicate that ADHD persistence rates from childhood into adulthood varies from a minimum of $4 \%$ to a maximum of $76 \%$, depending on differences in diagnostic criteria, procedure used, sample characteristics, informants, and the like [72]. Furthermore, a few longitudinal studies with strict diagnostic methodologies propose an ADHD symptom persistence rate of 40-60\% [73,74]. These results support the conclusion that ADHD can have a lifelong effect on an individual, rather than just being restricted to their childhood.

Recent changes in the ADHD diagnostic criteria in DSM-5, released in May 2013, are representative of perspective shift toward ADHD. These major modifications of ADHD classification and criteria in DSM-5 provide a guideline for appropriate ADHD diagnosis in adults [75]. First, ADHD, formerly classified under "disorders usually first diagnosed in infancy, childhood, or adolescence" in DSM-IV, is now listed under the "neurodevelopmental disorders" in DSM-5. This highlights its continuity throughout one's lifespan and bases the diagnosis on correlates of neural network development [76].

Second, the number of symptoms required to meet the inattention or hyperactivity-impulsivity criteria has been reduced from six to five out of nine symptoms in individuals aged 17 years and above, reflecting the possible age-dependent changes and natural course of the disorder. With requirement of fewer symptoms for a diagnosis, the proportion of individuals meeting the minimum threshold for either inattention or hyperactivity/impulsivity symptoms showed a significant $65 \%$ increase from $12.7 \%$ in DSM-IV to $21 \%$ in DSM-5 [77].

Third, the age of onset of noticeable inattentive or hyperactive-impulsive symptoms has been changed from 7 years to 12 years. This reflects the findings that $95 \%$ of adults presenting with ADHD recalled having symptoms before the age of 12 years, whereas only half the adults with ADHD recalled symptom onset by the age of 7 years [78]. Furthermore, although clear evidence of functional impairment is considered essential for ADHD diagnosis, it is no longer a requisite that the impairment should have occurred before the age of 12 years. This modification is significant since functional impairments induced by inattentive symptoms are more likely to be prominent later in life, such as in adolescence or adulthood, than in childhood. 
Fourth, the descriptions of symptom presentations have been made more elaborate with specific behavioral examples, making each criterion more applicable to adolescents or adults.

Fifth, age-adapted items for adolescents and adults have been clubbed with older terms for children in some criteria. For instance, adolescents or adults can be diagnosed as having hyperactivity symptoms with only a subjective feeling of restlessness or discomfort while waiting, whereas children are required to have active behavioral presentations. The previous categorization of three 'subtypes' in DSM-IV has been supplanted with an enumeration of "presentation specifiers" in DSM-5. While this clearly mirrors the previously employed subtypes, it accounts for temporal changes in patterns and severity of ADHD symptoms depending on age. Finally, the exclusion criterion of presence of a pervasive developmental disorder has been removed.

With all these changes, DSM-5 provides more comprehensive criteria for ADHD diagnosis allowing for adults previously misdiagnosed as in partial remission to now be diagnosed with fully developed ADHD. Indeed, a field trial prevalence study suggested that use of the modified DSM-5 accounted for a $27 \%$ increase in ADHD prevalence among young adults, from $2.8 \%$ with DSM-IV to $3.55 \%$ with DSM-5 [79]. This result confirms that lower cut-off points on number of symptoms, age-of-onset, and degree of impairment increases the sensitivity of adult ADHD diagnosis.

Despite the growing focus and literature on adult ADHD, little is known about adult ADHD in the Republic of Korea. There are very few studies examining the prevalence of ADHD in Korean adults. One study used epidemiological data and diagnostic interviews to suggest the 6-month prevalence of $\mathrm{ADHD}$ in participants between the ages of $18^{-59}$ years to be $1.1 \%$, with the symptoms being most prevalent in young adults [80]. More recent research evaluated a stratified sample of college students aged 18 years or older using a self-report measure. They derived a prevalence of $7.6 \%$, a higher percentage than the general adult population, and a higher prevalence of symptoms among subjects aged 18-20 years [81].

\section{Persistence of ADHD symptoms into adulthood}

In most cases, ADHD symptoms persist into adulthood and are accompanied by significant clinical disturbances. For instance, a review of longitudinal follow-up studies on individuals with childhood ADHD diagnosis showed that only $15 \%$ of the participants fulfilled all the criteria for ADHD diagnosis by the age of 25 years, indicating a low persistence of the disorder. However, when the criteria were relaxed to include those in partial remission as well, $65 \%$ reported to be continuously under the influence of the disorder [82]. Another, recent study on ADHD persistence found that although only
21.9\% of individuals who had been diagnosed with ADHD at 5-12 years still met full criteria even at 18 years of age, the majority of individuals had partial ADHD symptoms at 18 years of age and required continued clinical attention due to residual ADHD symptoms, comorbidity, and resulting functional impairment [65].

Few longitudinal studies have examined possible predictors for persistence of ADHD from childhood into late adolescence or adulthood. Though the findings are heterogeneous, a meta-analysis indicated that baseline ADHD characteristics such as severity of childhood ADHD symptoms are the most significant determinants of symptom persistence. These markers, coupled with comorbid major depressive disorder and conduct disorder have also been proposed predictors for the risk of persistence of ADHD. On the other hand, sociodemographic features such as gender, socioeconomic status, and IQ at baseline did not show any significant relationships with ADHD persistence [72].

\section{Clinical presentation of adult ADHD}

The symptoms of hyperactivity, impulsivity, and inattention have more subtle and varied presentations in adults, making them more difficult to detect. This could complicate and underrepresent ADHD diagnosis in adults. Hyperactivity in adults can be expressed as inner restlessness, excessive fidgeting, excess talkativeness, difficulty staying still, or inability to remain seated when requried. Attitudes and behaviors such as impatience, acting without prior thought, impulsive spending, need for excessive stimulation, difficulty in maintaining stable jobs, or starting relationships on impulse may be presentations of impulsivity. Inattention often expresses itself as being easily distracted, boredom, inablity to organize things and tasks, procrastination, and difficulty in decision-making [83]. It is particularly noticeable that, despite a general trend of the symptoms reducing with age, symptoms of inattention decline less than those of hyperactivity/impulsivity [84]. In fact, they sometimes stabilize with age [85-88] or even increase in a substantial number of individuals [89-91].

Clinical observations suggest that adult ADHD is related to more deficits in higher-level executive functioning and emotional control than in children [92,93]. In line with these observations, a number of researchers have attempted to examine the factor structure of ADHD symptoms unique to adults by including clinically observed symptoms beyond the DSM- 5 criteria. These primarily fall under the categories of executive dysfunction (poor time management, failure to finish tasks within a given time period or needing more time to produce satisfactory results, trouble planning ahead, and difficulty in multitasking) and emotional dysregulation (emotional lability, intolerance of stress, and inappropriate emotional over- 
reactions or outbursts). They derived factor structures and number of factors were heterogeneous across studies based on methods and samples used [94-97]. A recent study expanded the list of symptoms in both adult ADHD patients as well as a convenience sample. They confirmed a four-factor structure of adult ADHD comprising of executive dysfunction/inattention, hyperactivity, impulsivity, and lack of emotional control. The resulting symptom profiles for adults were similar to those given in DSM-5, with the predominantly hyperactive/impulsive presentation now limited to hyperactivity without high impulsivity.

ADHD symptoms and neuropsychological deficits disrupt individual capacities to cope with everyday demands [98], leading to extensive psychosocial impairments. This also increases vulnerability to stresses as well as the possibility of encountering additional adversities [99]. Such an imbalance between environmental demands and personal resources, which typically increases with age, can aggravate functional impairments in adults with ADHD. This implies that functional demands in scholastic, social, and occupational dimensions increase and become more complex with age, whereas the supportive resources available to ADHD patients (such as, guidance from parents or teachers) gradually reduce as time passes [100].

Young adults with ADHD are less likely to pursue post-secondary education [101]. In cases where they do enroll, they are less likely to graduate than peers without ADHD [102]. About $2-8 \%$ of college students suffer from clinical symptoms relevant to ADHD and $25 \%$ of college students who receive disabilities services are diagnosed with ADHD [102]. These students tend to experience academic problems such as lower grade point average, increased rates of academic probation, and poor time management and test taking abilities [102-104]. Nevertheless, some of them are able to maintain adequate academic performances and achievements, provided they receive appropriate and timely therapeutic interventions. Despite this, subjective reports on impaired executive functioning and cognitive failure are salient even in these cases [105].

Adults with ADHD usually experience difficulties in all dimensions of occupation starting from job search to job performance $[76,106]$. They are less likely to be under paid employment with only $22-24 \%$ of diagnosed individuals being hired $[107,108]$. According to a survey conducted by the WHO, about $3.5 \%$ of all workers suffer from ADHD and resulting work impairments [109]. Employment problems are further exacerbated by poor job performance [110], higher instances of annual absenteeism [109], more workplace accidents and injuries [111,112], and interpersonal problems possibly associated with mood instabilities like low frustration tolerance, irritability, and anger outbursts [93,113]. Military service is yet another index for social function as it is highly demanding and in the Republic of Korea, mandatory for men 19 years of age or older. Although ADHD diagnosis does not automatically exempt an individual from military service, young men with ADHD are medically unsuitable for military service in general and show lower functioning (availing more sick days and seeking more health care) [114]. They are not only more likely to have comorbid personality and minor mood disorders but are significantly more at risk of developing post-traumatic stress disorder [114,115]. A combination of lower intellectual capabilities and more psychiatric comorbidities may be predictive of poor adjustment outcomes in young adults with ADHD [68]. Adults with ADHD typically have short-lived or dysfunctional relationships. This is partly due to difficulty in paying careful attention to their partners, interrupting conversations often, and procrastinating assigned tasks [116]. More importantly, emotional symptoms (emotional lability, inappropriate emotional outbursts, stress intolerance), evident in 24-70\% of adults with ADHD [117], contribute significantly to maladjustments in personal relationships [118-121]. Such patients often have to handle not only regular parent-child relationships, but also face the possibility of having children with ADHD given the high rates of inheritance [122,123]. Other factors such as overdependence on partners and negative societal biases can also hinder seamless social functioning [124,125].

Adolescents/adults with ADHD are very susceptible to driving-related accidents due to high frequency of risky driving behaviors resulting from easy distraction and increased need for stimulation [113,126-128]. Young persons with ADHD are also more liable to exhibit unhealthy behaviors such as smoking, alcohol and illicit drug use, and risky sexual behaviors $[129,130]$. They also experience a rise in criminal behaviors, arrest, and incarceration [131,132], particularly with comorbidity of conditions such as conduct disorder, substance use disorder, or antisocial personality disorder [83,133]. Notably, the ADHD prevalence rate among adult prison inmates is $10.5 \%$, which is substantially higher than the rate among the general adult population $[134,135]$.

\section{DIAGNOSIS OF ADULT WITH ADHD}

\section{Considerations for diagnosis of adult ADHD}

Several issues which make diagnosis of adult ADHD challenging have been outlined here. First, core childhood ADHD symptoms (hyperactivity/impulsivity and inattention) change over time, suggesting a shift in clinical presentation with development $[53,136]$. For example, hyperactivity/impulsivity can manifest as "running about or climbing in situations where it is inappropriate" during childhood whereas it reveals itself 
as "feeling restless" during adulthood. Symptoms of ADHD in adults tend to be more heterogeneous and subtle than in children/adolescents as individuals have to manage more complex tasks and responsibilities they grow older.

Other prominent symptoms of ADHD also differ between in childhood and adulthood. Hyperactivity often declines by adolescence, while inattention is more persistent. Nearly 95\% of adults with ADHD have inattention problems whereas only $35 \%$ have hyperactivity issues [96]. Symptoms of impulsivity may convert to more subtle, intricate problems in executive functions, which are most pronounced in adult ADHD. Executive deficits cause adults with ADHD to experience difficulties in adaptive functioning (poor organization of money and time, failure to maintain routines) and eventually result in significant maladjustment [136]. Associated features such as mood lability, emotional overreaction, and sensitivity to stress are also frequent features of adult ADHD. Given these variations, closer examination of general functional impairments in daily life and accounting for symptom variations between adolescents and adults, as suggested by DSM-5, are recommended for accurate diagnosis.

Diagnosis of ADHD in adults is contingent on self-reportage, whereas in childhood it is often supported by information from additional informants such as parents and teachers. Self-reports on past and present symptoms as well as the level of daily functioning are only reliable when individuals are well aware of their conditions [137]. Even in such cases, retrospective recall of childhood symptoms may be inaccurate. It has also been observed that persistence rates of ADHD symptoms from childhood to adulthood were lower when the condition was self-reported by adolescents or young adults as opposed to their parents [136]. In the light of these caveats, the accuracy of self-reported symptoms is a subject of some debate. Some adolescents or young adults struggling with identity issues are likely to underestimate their ADHD symptoms whereas others may exaggerate them $[136,138]$. Although diagnosis based solely on self-report is possible, this practice comes with a risk of misdiagnosis based on lack of accuracy in the self-reports. Therefore, for better reliability and correct diagnosis, it is recommended that the mental health practitioner acquire additional information from collateral informants such as parents, elder relatives, partners, close friends, or relatives [83].

The symptoms of adult ADHD usually co-exist with other psychiatric conditions in adolescents and adults [139]. In adolescents, assessment and treatment may be focused only on ADHD symptoms, while other comorbidities are ignored. On the other hand, in adults, symptoms of ADHD are less likely to be recognized and dealt with since the comorbid conditions are often the focus of attention [136]. This makes di- agnosis of adult ADHD complicated, as individuals develop specific coping strategies for other mental health issues [140]. Even if one were to account for all the above complications, detecting ADHD symptoms in high-functioning individuals is no easy task as many patients have strategies to compensate for impairments caused by their deficits in attention and executive functions. Such shortcomings can be bypassed with thorough investigations of childhood and family histories, social and occupational functional levels, and scores on screening tests.

\section{The evaluation process}

Diagnosing ADHD in adults requires comprehensive and systematic evaluation based on multiple factors, including assessment of the lifetime history of symptoms and impairments. These symptoms range from inattentive or hyperactive/impulsive symptoms prior to 12 years of age to symptoms at the current age. The functional impairments should be present in at least two of the following domains: school, work, home, interpersonal situations, or other. Considering that deficits in executive function are a key feature of adult ADHD, mental health professionals should carefully examine associated features such as lowered inhibition (mood lability, temper outbursts) and other related impairments (relationship issues such as divorce and multiple marriages). Given the high heritability of ADHD, it is also important to screen for any familial history of psychiatric and neurological conditions, symptom patterns and comorbidities in family members [83].

The degree of functional impairment can be assessed through interviews with afflicted individuals and significant others such as parents or spouses. The general assessment covers aspects of the individual's life where ADHD symptoms compromise adequate functioning, such as work, social life, interpersonal relationships, life goals, and overall behaviors (risky driving and substance abuse). It is usually imperative to refer to collateral information (significant others, school or criminal records) since quite a few adults with ADHD are poor at recognizing any functional impairments caused by the symptoms. Nevertheless, self-referred individuals are likely to be well aware of their symptoms and dysfunctions, leading them to seek evaluation and professional help. The other important criterion in determining functional impairment is the amount of effort individuals invest in order to accomplish tasks. Adults with ADHD may not reveal failures or may appear successful since they can develop a variety of skills and coping mechanisms (organizational, motoric, attentional, social, and psychopharmacological) to compensate [140]. Thus, it is vital to evaluate whether an individual expends excessive amounts of time and energy in order to simply attain basic level of functionality [136]. 
In order to determine whether an individual's symptoms can be attributed to other psychiatric conditions, it is important to take a full medical history of psychiatric and somatic problems and treatments. Given that it is uncommon to see adults presenting solely with ADHD and as other conditions are frequently comorbid, clinical assessments of adult ADHD must always take into consideration co-existing symptoms and disorders. In adults, ADHD is frequently a part of mood disorders, anxiety disorders, substance use disorders and impulse control disorders [78]. The presence of such comorbid psychiatric conditions significantly affects the diagnosis and outcomes of treatment $[141,142]$. A survey conducted by KACAP-AASIG [1] revealed that at initial clinical presentation at the first visit, $51.09 \%$ of patients with adult ADHD showed ADHD core symptoms while 40.57, 28.37, 21.31, and $20 \%$ of patients showed depressive disorder symptoms, anxiety disorder symptoms, substance use disorder symptoms, and bipolar disorder, respectively. Although symptoms of ADHD (inattention, impulsivity) can also be a part of other psychiatric disorders, it is typical for ADHD to have early onset, usually by childhood, and have a prolonged course. When compared to other disorders, ADHD shows consistently higher instances of distractibility, impulsivity, and deficits in executive function and self-regulation [143]. Although these are less frequently studied in adults, several neurodevelopmental traits and disorders such as (autism spectrum disorders, dyslexia, and impaired motor coordination) are also highly comorbid with ADHD [144-146].

\section{Screening and evaluation instruments}

ASRS is the one of the most widely used rating scales for adult ADHD. The ASRS includes items for each of the 18 DSM-IVTR criteria, which were reworded to better depict the clinical presentation of ADHD in adults. It comprises of a 6-item Part $A$ and a 12-item Part B. Individuals are required to rate their symptoms based on their occurrence and frequency over the past 6 months rather than the severity of symptoms [147]. The 6-item part A serves as short screening scale for clinical utility, meeting the threshold of which is highly predictive of symptoms consistent with ADHD. The frequency scores of Part B provide additional information on the symptoms. The Korean version of ASRS also has sound psychometric properties [2]. According to a study on the clinical utility of the Korean version of ASRS, the screener was sound in terms of sensitivity and specificity, with its strength in easy and quick administration though the ASRS total score outperformed. The cut-off score of the Korean scale has been set at 32 [148]. Recent updates are being made reflecting the changes made in DSM-5 criteria [149].

Self-report questionnaires can be used as a part of a com- prehensive diagnostic assessment process. For instance, the Conners' Adult ADHD Rating Scales (CAARS) are designed to assess ADHD in adults aged 18 through 50 years and older [150]. In addition to providing T-scores specific to gender and age group, each item in CAARS is useful in differentiating individuals with or without ADHD. The CAARS utilizes six forms (short/long/screening coupled with self-report/observer rating scale form). The WURS comprises of 61 items, with 25 items in its short form. It helps individuals with adult $\mathrm{ADHD}$ to retrospectively remember childhood symptoms, establishing the existence of ADHD [151]. Current symptoms in adulthood can be assessed using Brown Attention Deficit Disorder Rating Scale for Adults (BADDS). The BADDS comprises of 40 items. Although it originally required researchers to read the questions and fill the form, the manual also allows written self-assessment by adults. The BADDS for Adults focuses on symptoms ranging from inattention to executive function impairments, all of which are usually encountered by adults with ADHD (managing affective interference, organizing and initiating the work). In this regard, the BADDS can help to identify areas of difficulty for individual patients [152]. The Current Symptoms Scale (CSS) [153] is a self-report/observer rating scale which examines ADHD symptoms in correspondence with DSM-IV diagnostic criteria, ADHD-dependent functional deficits in various settings, and symptoms of oppositional defiant disorder in the past 6 months. The Young ADHD Questionnaire-Self-Report (YAQ-S) and Young ADHD Questionnaire-Informant-Report (YAQ-I) were developed to investigate current functioning. Items in YAQ-S and YAQ-I were chosen based on a review including ADHD symptoms as well as frequently comorbid conditions (delinquency, emotional problems) [154].

In Korea, the K-AARS was developed by reviewing items from five commonly used rating scales for adult ADHD overseas-CAARS, BADDS, WURS, ASRS, and CSS [4]. The KAARS is a self-report rating scale consisting of 73 items and eight sub-factors including inattention, hyperactivity, impulsivity, antisocial personality disorder/conduct disorder/oppositional defiant disorder, impairment, driving, emotional dysregulation, and disorganization. The K-AARS is special in that it includes antisocial personality disorder/conduct disorder/oppositional defiant disorder as an independent factor and also has a set of cut-off score [155]. The Barkley Deficits in Executive Functioning Scale (BDEFS) was specifically designed for evaluating the deficits in executive functioning (time management, organization and problem solving, selfrestraint, self-motivation, and self-regulation) in adults with ADHD [156] and was later standardized in Korean [157].

Although self-report scales are informative and useful in guiding diagnosis, a diagnostic interview is fundamental to 
assessment and advisement. DIVA was originally developed based on DSM-IV criteria in Dutch and translated into multiple languages [158]. The DIVA-5, which has been upgraded based on DSM-5, is available in Dutch, English, and Korean versions [5]. This semi-structured interview consists of 18 DSM-5 criteria for ADHD and specific examples for each criterion that the interviewer can use to evaluate the presence or absence of symptoms. It is also useful in specifying the extent and areas of dysfunction associated with symptoms by providing specific categories of daily functioning (work/education, relationship and/or family, social contacts, free time/ hobby, and self-confidence/self-image) with detailed examples. The Conners' Adult ADHD Diagnostic Interview for DSM-IV (CAADID) is a semi-structured interview designed for accurate and appropriate diagnosis of ADHD in adults [159]. The CAADID is divided into two parts: part I is designed to gather information related to demographic history, developmental course, ADHD risk factors, and brief comorbid psychopathology screening whereas part II is diagnostic interview designed to assess DSM-IV ADHD criteria and is administered by a trained clinician.

Currently, there are no neuropsychological tests for ADHD with established diagnostic applications. Adults with ADHD significantly differ from those without ADHD and even from adults with other psychiatric disorders in terms of scores on neuropsychological tests such as Comprehensive Attention Test (CAT) [160], Conners' Continuous Performance Test (CPT), Digit Span and Letter-Number Sequencing of WAIS, Go/No-Go Task, Stroop Word Color Test, and verbal memory tests including Rey Auditory Verbal Learning Test and the Logical Memory subtest of the Wechsler Memory ScaleRevised [161-165]. Poor performance on these neuropsychological tests indicates that adults with ADHD are likely to have cognitive impairments in vigilance and sustained attention, verbal working memory, memory acquisition and resulting long-term memory formation, and notably in executive function (inhibition, set shifting). Nevertheless, cognitive performance is not predictive of presence or absence of ADHD in adults and thus adult ADHD cannot be determined by these test results alone. Cognitive performance needs to be used for establishing treatment paradigms and prognosis of the disorder.
According to the survey by the expert consensus of psychiatrists on diagnosis and treatment of adults with ADHD, the most commonly used diagnostic evaluation methods in current practice are clinical psychiatric interview (20.66\%) and self-report scale (19.25\%) followed by attentional (14.71\%) and psychological tests (14.24\%). As per textbooks, however, the most commonly used evaluation methods are self-report scale (25.38\%), clinical psychiatric interview (23.48\%), psychological (16.67\%), and attentional tests (15.72\%) [1]. Table 1 summarizes the key evaluation instruments currently available in Korea.

\section{Differential diagnosis and comorbidity}

$\mathrm{ADHD}$ is often associated with a high rate of comorbid psychiatric disorders in both children and adults. Between 65$89 \%$ of adults with ADHD present with one or more additional psychiatric conditions, with the average number of comorbid disorders being three $[166,167]$. Mood disorder, anxiety disorders, substance use disorders, personality disorders, learning difficulties, and nicotine dependencies are the most prevalent of these [167-169]. Adult ADHD is not only associated with comorbidity and severity of addictions such as substance, gambling, internet, and video gaming, but also with an earlier onset of addiction and poly-dependence [170-172]. Although it is possible to identify whether an individual has ADHD or not, accurate identification of ADHD-specific symptoms and clear judgment on ADHD treatment in the light of other comorbid disorders can be challenging [173].

In this regard, it is important to identify comorbid conditions when assessing ADHD. Approximately 38.3\% of adults with ADHD have a comorbid mood disorder. Comorbid depression is also common with a higher prevalence of both major depressive disorder and dysthymic disorder in adults with ADHD than in non-ADHD adults. Furthermore, adults with ADHD often present with low self-esteem, demoralization, dysthymic mood, poor concentration, attention and memory, restlessness, and irritability, which may obfuscate the diagnosis of ADHD. However, it is not common for ADHD without depressive disorders to be associated with a sustained depressive mood, excessive guilt, or suicidal ideations. Bipolar disorders co-occur in approximately $20 \%$ of adult ADHD

Table 1. Key evaluation instruments currently available in Korea

\begin{tabular}{ll}
\hline Self-report scale & WHO Adult ADHD Self-Report Rating Scale (ASRS) [2, 148] \\
& Korean Adult ADHD Rating Scale (K-AARS) [155] \\
Executive functioning scale & Barkley Deficits In Executive Functioning Scale (BDEFS) [157] \\
Diagnostic interview & The Diagnostic Interview for ADHD in Adults (DIVA-5) [5] \\
Attentional test & Conners' Continuous Performance Test (CPT) \\
& Comprehensive Attention Test (CAT) [160] \\
Neuropsychological test & Digit Span and Letter-Number Sequencing of Wechsler Adult Intelligence Scale [161-164]
\end{tabular}


cases [174]. Affective lability and irritability in ADHD overlap with bipolar disorders and, more importantly, symptoms of ADHD are often erroneously regarded to be a part of bipolar disorders. As a result, ADHD comorbid with bipolar disorders is likely to be under-diagnosed and under-treated [175]. Mood changes in ADHD are usually presented as continuous poor regulation within the normal range of moods, whereas mood instability in bipolar disorders is episodic, with severe extremes of depression and elation accompanying delusions or hallucinations.

Anxiety disorders are among the most frequently coexisting diagnoses in adults, with $23-47.1 \%$ of adults with ADHD having anxiety disorder $[174,176]$. These usually deteriorate over time since individuals experience more difficulties handling tasks and taking on responsibilities which require increasingly higher cognitive abilities. Generalized anxiety disorder (GAD) is one of the most commonly co-occurring anxiety conditions. The high rate of co-occurrence may be partially explained by symptomatic overlap between two disorders such as inattention, difficulty in concentrating and restlessness [177, 178]. However, even upon excluding the overlapping symptoms, $75 \%$ of individuals with ADHD meet the diagnosis of GAD, indicating a high comorbidity rate between the two conditions [179]. Although not all the diagnostic criteria for GAD are met, adults with ADHD often feel consistently anxious and apprehensive about their performance on studies, jobs, and other duties. This anxiety further impairs the capacity to concentrate and is often associated with maladaptive coping mechanism such as avoidance or procrastination [180]. On the other hand, purely anxious individuals are less likely to have executive dysfunction and may present better performance on tasks once engaged and distracted from worries. In adults with ADHD these conditions further intensify anxiety [181].

Both ADHD and borderline personality disorder (BPD) may be considered developmental since they emerge during childhood or adolescence [182]. ADHD and BPD share similar clinical features including impulsivity, affective instability, emotional dysregulation, and unstable interpersonal relationships [182-184]. On the other hand, symptoms such as chronic suicidality, self-mutilation, feelings of abandonment and emptiness, stress-related paranoid ideation or dissociation are typical of BPD but not of ADHD [184,185]. The distinction between these two disorders is not clear as symptoms of both are enduring and trait-like (non-episodic).

\section{TREATMENT OF ADULTS WITH ADHD}

\section{Treatment approach}

As with treatments for childhood/adolescent ADHD, the treatment for adults can follow a multimodal and multidis- ciplinary approach including psychoeducation, pharmacotherapy, cognitive behavior therapy (CBT) and coaching for ADHD. When compared to childhood/adolescent ADHD, adult $\mathrm{ADHD}$ requires tailor-made treatments regimens given the wide range of psychosocial and psychological characteristics. The administered course of therapy should be especially considerate of the individual's partner, family and close relationships. When adults with ADHD were diagnosed with a degree of problems such that it continuously disrupted family relationships, the patients were asked to attend family or couples therapy alongside the regular treatment for ADHD.

\section{Considering comorbidities in adult ADHD}

Careful diagnostic assessment can ensure that any comorbid disorders of ADHD are accounted for in the ADHD treatment plan. Depending on the type and severity of the comorbidity, a given plan of ADHD treatment should assess and control for the comorbidities from the very beginning of ADHD treatment especially with respect to the order of pharmacological treatment. Of the various psychiatric comorbidities of adult $\mathrm{ADHD}$, higher frequencies were seen with the following: anxiety disorder, mood disorder, behavioral disorder and substance use disorder. In addition, the orders of treatment should be in keeping with the severity of psychiatric disorders: psychosis, bipolar disorder, substance abuse, severe depression and severe anxiety should be prioritized. Milder depressive or anxiety disorders, and unstable mood may follow the treatment of ADHD. Conditions like substance abuse, including drug and alcohol abuse, can be stabilized or treated alongside ADHD.

\section{Psychoeducation}

Of the various treatment modalities for ADHD, most clinical practices declare that psychoeducation should be the first choice of standard care [186]. Psychoeducation covers ADHD symptoms and impairment, its prevalence in children and adults, frequency of comorbidities, heritability, accompanying brain dysfunctions, and their functional consequences, as well as the available treatment options. In fact, the very act of providing knowledge and information about ADHD could improve patient understanding and make them more comfortable in handling the condition. This avenue of treatment processing also allows patients to obtain new insights into previous difficulties experienced due to ADHD. In the past, patients with ADHD faced significant levels of failure and difficulties in their lives, often stigmatized as inadequacy. Psychoeducation would enable the patient to gain perspective on the disorder and accordingly plan for the future. In addition, their social relationships may be reframed without feelings of guilt and remorse within family members and others. 


\section{Pharmacotherapy}

\section{Introduction to pharmacotherapy}

As with childhood/adolescent ADHD, pharmacotherapy for adult ADHD can highly effective [83], and is often recommended as the first-line of treatment for adult ADHD by the National Institute for Health and Clinical Excellence (NICE) [187]. Of the several options available for ADHD, stimulants were the first choice for treatment of adult ADHD [83,187-190]. The non-stimulant ATX is recommended as a second-line of treatment, followed by other non-stimulants such as bupropion and tricyclic antidepressants [83,187,191].

In Korea, the following medications have been approved by the Korean Food and Drug Administration (KFDA) for treatment of adult ADHD: methylphenidate $\mathrm{HCl}$ ER (Concerta ${ }^{\circledR}$ OROS, Metadate ${ }^{\circledR} \mathrm{CD}$, Medikinet ${ }^{\circledR}$ Retard, Bisphentin ${ }^{\circledR} \mathrm{CR}$ ) and atomoxetine (Strattera ${ }^{\circledR}$, Atomotter $^{\circledR}$, Atomoxin $^{\circledR}$, Atomoxetine $^{\circledR}$, Artlex $^{\circledR}$, Atocera $^{\circledR}$ ).

\section{Stimulants}

For ADHD, data on effectiveness and safety point to stimulants (dexamphetamine, methylphenidate) as the preferred drug treatments [187,192]. Treatment with stimulants improves the behaviors and symptoms associated with ADHD. It also improves related problems of lowered self-esteem, mood swings, irritability, cognitive impairments and social function.

Methylphenidate (MPH) is the most widely studied stimulant of those used for ADHD treatment. MPH can be used in a variety of formulas, including immediate release (IR) and extended release (ER) formulations. There are many other stimulant options available, depending on the country.

Approximately $70 \%$ of patients treated in this manner respond to the first prescribed stimulant [83]. Meta-analyses of randomized control tests (RCTs) demonstrate the efficacy of stimulants and ATX in reducing ADHD symptoms in adults. Stimulants showed greater efficacy than ATX, with their standardized mean differences (SMDs) ranging from 0.4 to 0.7 [191]. An RCT conducted in 2015, the longest ever conducted in adults, still found significant effects of MPH a year after administration [193]. Swedish national registration data also suggest long-term benefits of treatment with ADHD drugs, with traffic accidents and deaths, criminal convictions, violent re-offences, depression, suicidal behavior, or substance misuse significantly decrease during the period of treatment [194-198]. No effect was found in similar analyses of antidepressants, suggesting that the effects are specific to ADHD drugs.

\section{Derivatives of amphetamine}

The recommended dose range of dextroamphetamine (IR) is 5-60 mg/day [189]. Lisdexamfetamine (LDX) has a slow release profile, which allows a relatively low abuse profile [199]. LDX is recommended to be taken once daily, and its effect can last up to 14 hours [200]. Three RCTs conducted in adults reported moderate to large effects of LDX on ADHD symptoms [201-203] comparable to MPH (SMD=0.97) [204]. The tolerability and safety profile is similar to other stimulants [205, 206]. Unfortunately, this medicine is not available in Korea.

\section{Methyphenidate}

A meta-analysis published in 2011 [207] suggested that MPH (mean dose 41.2-82 mg/day) has a moderate effect on ADHD symptoms, with large effects at doses of $>77.4 \mathrm{mg} /$ day. MPH (IR) has a short duration of action with a maximum 4 hours. The short effect time mandates several doses a day, which ADHD patients often fail to comply with. To counteract this, long-acting MPH preparations have been developed with durations of action ranging from 6-12 hours.

Stimulants are generally well tolerated by ADHD patients. The main adverse effects of stimulants include dry mouth, nervousness, headache, decreased sleep and appetite, and elevated heart rate and blood pressure [208-211]. Therefore, the body weight, heart rate, blood pressure, and any sleep problems should be assessed beforehand, and monitored at least twice a year during treatment. Serious cardiovascular complications are rare [209,212,213], with one study reporting risks for ventricular arrhythmias, myocardial infarction, sudden cardiac death, or stroke no more than $0.2-0.4 \%$ higher than normal [214]. MPH may trigger arrhythmias in patients with congenital heart diseases [215]. Given these possible adverse effect, the consensus has been to take caution in patients with known cardiac defects, eventhough risks are low.

\section{Atomoxetine}

ATX, a norepinephrine reuptake inhibitor, is an alternative non-stimulant option and has been shown to be effective in treating adults with ADHD [202-205]. Around two-thirds of patients respond to ATX. When compared to MPH, ATX was thought to have moderate efficacy in reducing ADHD symptoms [216]. ATX may be good for ADHD patients with co-occurring anxiety that could be exacerbated by stimulants [217]. ATX seems to be ineffective in the treatment of comorbid depression in adolescents with ADHD [218]. Typical side effects are somewhat similar to stimulant medications and include noradrenergic effects such as alteration of heart rate and blood pressure, and erectile dysfunction [219,220].

\section{Bupropion}

Several studies in adults have reported contradictory findings for bupropion. Positive results were reported with high- 
er doses (400-450 mg/day) [221,222]. Given that the evidence base is limited, bupropion use should be restricted to patients who do not tolerate other ADHD medications.

\section{Guanfacine and clonidine}

Guanfacine ER (GXR), an $\alpha-2$ adrenergic agonist, is approved in the US and Europe for the treatment of childhood/ adolescents ADHD in cases where use of stimulants is not appropriate, not tolerated or not effective $[223,224]$. Guanfacine IR is approved in the US for use in both children and adults with ADHD (both as monotherapy and in combination with stimulants). Till date, there have been no RCTs in adult ADHD patients to support the use of GXR in this age group. One study using GXR or placebo as an adjunct to stimulant showed insufficient effects, since both treatments has similar efficacies [225]. This drug is currently not available in Korea.

Clonidine ER is approved in the US for treatment of ADHD in 6-17 year olds as monotherapy or as an adjunct to stimulants. RCTs have been performed on both clonidine ER [226, $227]$ and IR $[228,229]$ in children and adolescents with ADHD, but not in adults.

\section{Combination pharmacotherapy}

In Korea, in spite of single ADHD medication for at least one month, another type of medication (MPH, ATX, clonidine) can be added when there is not enough clinical response from December, 2019.

\section{Other medications}

Tricyclic antidepressants have limited evidence regarding the efficacy of ADHD treatment. Selective serotonin reuptake inhibitors have shown to be ineffective for the treatment of ADHD [197,198,230-232]. Modafinil, a wakefulness-promoting agent used in treating narcolepsy, has also proven to be ineffective for adult ADHD in a phase three trial [233]. However, there is some evidence to show that selective noradrenaline reuptake inhibitors such as reboxetine could be an alternative to ATX [234,235].

\section{CBT and coaching for ADHD}

As a multi-modal treatment approach, $\mathrm{CBT}$ is one of best options that can be supplemented by medication [236-239]. In group or individual settings, CBT can improve ADHD symptoms, emotion dysregulation, anxiety, mood, and functional impairments in adults with ADHD [193,240-242]. CBT may also play a critical role in the management of adults with $\mathrm{ADHD}$ who are motivated and developmentally ready to acquire new skills as symptoms remit [243]. Most CBT programs are skillsbased and focus on organizational and time management skills, prioritization, motivation, emotional regulation/control, problem solving skills, prosocial competence and strategies to improve attention and impulsivity management.

\section{Current treatment trends for adult ADHD in Korea [1]}

A survey was conducted on 142 psychiatrists currently treating adult ADHD patients in the Republic of Korea [1]. They were asked a series of questions on their current clinical experience in treating adult ADHD. Of the 142 psychiatrists, 56 had had additional child and adolescent psychiatry (CAP) training.

\section{First line of treatment for adult ADHD}

One hundred six psychiatrists (75.2\%) answered that medication was the first choice of treatment for adult ADHD. The second popular choice was psychoeducation (51.1\%), followed by CBT (38.5\%). This was consistent in both groups with and without CAP training. An interesting fact to note is that psychiatrists with CAP training had somewhat mixed opinions on the first choice of treatment, with no clear winner between psychoeducation (35.7\%) and medication (64.3\%). This was very different when compared to the psychiatrists without CAP training, who showed a high tendency to select medication as the first choice (82.4\%) followed by psychoeducation (16.5\%).

\section{Medications used in adult ADHD}

Most psychiatrists used the long acting MPH osmotic-release oral system. The second most common choice was ATX, and the third was MPH IR.

\section{Mean medication dosage}

Psychiatrists with CAP training tended to use medication much higher dosage than those without CAP training, with the exception of clonidine. This may be due to the fact that psychiatrists with CAP training have more experience with ADHD medication and therefore have more confidence in dealing with high dosage situations such as managing side effects.

Treatment options when first medication has low efficacy or side effects

Most psychiatrists chose to change the medication when the first choice of medication failed to work or had side effects (68.1\%). The second choice was to combine the first drug with another ADHD medication (24.4\%). Notably, no psychiatrists chose to forgo medication altogether. This may indicate that psychiatrists consider the symptoms of adult ADHD severe enough that they cannot be managed without medication. 


\begin{abstract}
Average period of treatment for adult ADHD informed to the patient

Most psychiatrists informed their patients that the average treatment period for adult ADHD is over 3 years (33.1\%). Psychiatrists with CAP training recommended between 2 and over 3 years ( $30.2 \%$ and $34.0 \%$, respectively), with the majority slightly leaning to over 3 years. In contrast, psychiatrists without CAP training had a broader sense of average treatment periods, ranging from 6-12 months to 2 years and over 3 years $(27.5,22.5$, and $32.5 \%$, respectively).
\end{abstract}

\section{Average period of actual treatment for adult ADHD}

Although psychiatrists tended to explain to their patients that over 3 years of treatment is required, in clinical settings, the actual average treatment period was between 6 and 12 months (44.7\%). This could be due to doctors exaggerating the treatment period in fear of early dropout before adequate treatment was administered. Psychiatrists with CAP training had a much longer average treatment period when compared to those without CAP training.

\section{Thoughts on the side effects of adult ADHD medication}

The survey had four levels of side effects: mostly temporary and safe to use, tolerable enough to use for the pharmacological effects, moderate side effects, and severe side effects. Most psychiatrists (48.9\%) thought that the side effects of adult ADHD medications are mostly temporary, making them safe to use. However, average opinions differed between psychiatrists with and without CAP training. Psychiatrists with CAP training mostly answered that the side effects of adult ADHD medications are temporary and safe (61.1\%), whereas among psychiatrists without CAP training, the majority answered that although there are some side effects, it is tolerable enough to use for the pharmacological effects (46.9\%).

\section{CONCLUSION}

ADHD symptoms during childhood continue throughout adolescence and into adulthood. Adults with ADHD face lifelong negative impacts of the disorder and require close long-term follow-up. Hence, an established Korean practice parameter for adult ADHD is necessary to minimize any discontinuation of treatment and allow for information exchange among mental health professionals. The currently available screening instruments in Korea are the WHO ASRS and KAARS. For confirming the diagnosis of adult ADHD, psychiatrists can use DIVA-5. A survey among the Korean experts showed that the most psychiatrists answered that medication was the first choice of treatment for adult ADHD. The second popular choice was psychoeducation, followed by
CBT.

The Korean practice parameter provides globally accepted general information on diagnosis and treatment for adult $\mathrm{ADHD}$ as well as the diagnostic evaluation processes and treatment options applicable to Korean adults with ADHD. This Korean practice parameter will be a first step introducing the fields to discuss and share the information to diagnosis and treatment of Adult ADHD among the Korean mental health practitioners.

\section{Acknowledgments \\ None \\ Conflicts of Interest}

The authors have no potential conflicts of interest to disclose.

\section{Author Contributions}

Conceptualization: Geon Ho Bahn, Young Sik Lee, Hanik K Yoo, EuiJung Kim, Subin Park, Doug Hyun Han, Minha Hong, Bongseog Kim, Soyoung Irene Lee, Soo Young Bhang, Jin Pyo Hong, Yoo-Sook Joung. Data curation: Hanik K Yoo, Doug Hyun Han, Minha Hong, Bongseog Kim, Seung Yup Lee. Formal analysis: Hanik K Yoo, Doug Hyun Han, Minha Hong, Bongseog Kim, Seung Yup Lee. Methodology: Geon Ho Bahn, Young Sik Lee, Hanik K Yoo, Doug Hyun Han, Minha Hong, Bongseog Kim, Yoo-Sook Joung. Supervision: Geon Ho Bahn, Young Sik Lee, Yoo-Sook Joung.

\section{ORCID iDs}

Geon Ho Bahn https://orcid.org/0000-0002-3550-0422

Young Sik Lee https://orcid.org/0000-0003-2161-8232

Hanik K Yoo https://orcid.org/0000-0001-7118-604X

Eui-Jung Kim https://orcid.org/0000-0002-6369-5167

Subin Park https://orcid.org/0000-0002-4623-9899

Doug Hyun Han https://orcid.org/0000-0001-5888-0686

Minha Hong https://orcid.org/0000-0003-4924-1107

Bongseog Kim https://orcid.org/0000-0002-2534-6986

Soyoung Irene Lee https://orcid.org/0000-0003-2473-2954

Soo Young Bhang https://orcid.org/0000-0001-5254-0314

Seung Yup Lee https://orcid.org/0000-0003-4120-5603

Jin Pyo Hong https://orcid.org/0000-0001-5384-2605

Yoo-Sook Joung https://orcid.org/0000-0002-9225-4643

\section{REFERENCES}

1) Hong M, Lee S, Lee YS, Kim B, Joung YS, Yoo HK, et al. Comparison of attention-deficit/hyperactivity disorder practice in adults according to a training background in child psychiatry. $\mathrm{J}$ Korean Acad Child Adolesc Psychiatry 2019;30:121-126.

2) Kim JH, Lee EH, Joung YS. The WHO Adult ADHD Self-Report Scale: reliability and validity of the Korean version. Psychiatry Investig 2013;10:41-46.

3) Kim MS. 9 out 10 adult ADHD patients suffer from other mental diseases such as depression: announcement of 100 psychiatrists' survey, Korean Academy Child and Adolescent Psychiatry. 2nd ADHD Day Press Meeting: results of survey on adult ADHD disease awareness and treatment 2017. Yonhap News (Seoul). 2017 Mar 28 [cited 2019 July 15]. Available from URL: https:// www.yna.co.kr/view/AKR20170328139200017.

4) Kang T, Kim J, Bahn GH, Song SH, Kim J, Kim J, et al. Develop- 
ment of Korean Adult ADHD Rating Scale. J Korean Acad Child Adolesc Psychiatry 2015;26:295-310.

5) DIVA Foundation. DIVA-5 [cited 2019 July 1]. Available from URL: http://www.divacenter.eu/DIVA.aspx?id=523.

6) Lee S, Choi J, Kim K, Kim JW, Kim S, Kang T, et al. The guideline of diagnosis and treatment of attention-deficit hyperactivity disorder: developed by ADHD Translational Research Center. J Korean Acad Child Adolesc Psychiatry 2016;27:236-266.

7) Barkley RA. Attention-deficit hyperactivity disorder: a handbook for diagnosis and treatment. 3rd ed. New York: The Guilford Press;2006. p.219-247.

8) Biederman J, Faraone SV, Mick E, Spencer T, Wilens T, Kiely K, et al. High risk for attention deficit hyperactivity disorder among children of parents with childhood onset of the disorder: a pilot study. Am J Psychiatry 1995;152:431-435.

9) Biederman J, Faraone S, Milberger S, Curtis S, Chen L, Marrs A, et al. Predictors of persistence and remission of ADHD into adolescence: results from a four-year prospective follow-up study. J Am Acad Child Adolesc Psychiatry 1996;35:343-351.

10) Biederman J, Mick E, Faraone SV. Age-dependent decline of symptoms of attention deficit hyperactivity disorder: impact of remission definition and symptom type. Am J Psychiatry 2000; 157:816-818.

11) Faraone SV, Biederman J, Feighner JA, Monuteaux MC. Assessing symptoms of attention deficit hyperactivity disorder in children and adults: which is more valid? J Consult Clin Psychol 2000;68:830-842.

12) Faraone SV, Mick E. Molecular genetics of attention deficit hyperactivity disorder. Psychiatr Clin North Am 2010;33:159-180.

13) Boomsma DI, Saviouk V, Hottenga JJ, Distel MA, de Moor MH, Vink JM, et al. Genetic epidemiology of attention deficit hyperactivity disorder (ADHD index) in adults. PLoS One 2010;5: e10621.

14) Kan KJ, Dolan CV, Nivard MG, Middeldorp CM, van Beijsterveldt CE, Willemsen G, et al. Genetic and environmental stability in attention problems across the lifespan: evidence from the Netherlands twin register. J Am Acad Child Adolesc Psychiatry 2013;52:12-25.

15) Larsson H, Asherson P, Chang Z, Ljung T, Friedrichs B, Larsson JO, et al. Genetic and environmental influences on adult attention deficit hyperactivity disorder symptoms: a large Swedish population-based study of twins. Psychol Med 2013;43:197-207.

16) Brikell I, Kuja-Halkola R, Larsson $H$. Heritability of attentiondeficit hyperactivity disorder in adults. Am J Med Genet B Neuropsychiatr Genet 2015;168:406-413.

17) Zhou K, Dempfle A, Arcos-Burgos M, Bakker SC, Banaschewski $\mathrm{T}$, Biederman J, et al. Meta-analysis of genome-wide linkage scans of attention deficit hyperactivity disorder. Am J Med Genet B Neuropsychiatr Genet 2008;147B:1392-1398.

18) Zhu M, Zhao S. Candidate gene identification approach: progress and challenges. Int J Biol Sci 2007;3:420-427.

19) Grevet EH, Marques FZ, Salgado CA, Fischer AG, Kalil KL, Victor MM, et al. Serotonin transporter gene polymorphism and the phenotypic heterogeneity of adult ADHD. J Neural Transm (Vienna) 2007;114:1631-1636.

20) Lasky-Su J, Lange C, Biederman J, Tsuang M, Doyle AE, Smoller JW, et al. Family-based association analysis of a statistically derived quantitative traits for ADHD reveal an association in DRD4 with inattentive symptoms in ADHD individuals. Am J Med Genet B Neuropsychiatr Genet 2008;147B:100-106.

21) Lasky-Su J, Neale BM, Franke B, Anney RJ, Zhou K, Maller JB, et al. Genome-wide association scan of quantitative traits for attention deficit hyperactivity disorder identifies novel associations and confirms candidate gene associations. Am J Med Genet B Neuropsychiatr Genet 2008;147B:1345-1354.

22) Lasky-Su J, Anney RJ, Neale BM, Franke B, Zhou K, Maller JB, et al. Genome-wide association scan of the time to onset of attention deficit hyperactivity disorder. Am J Med Genet B Neuropsychiatr Genet 2008;147B:1355-1358.

23) Hong JH, Hwang IW, Lim MH, Kwon HJ, Jin HJ. Genetic associations between ADHD and dopaminergic genes (DAT1 and DRD4) VNTRs in Korean children. Genes Genomics 2018;40: 1309-1317.

24) Kim BN, Kang D, Cho SC, Park TW, Lim MH, Chung YC, et al. Shorter dinucleotide repeat length in the DRD5 gene is associated with attention deficit hyperactivity disorder. Psychiatr Genet 2009;19:57.

25) Hawi Z, Cummins TD, Tong J, Johnson B, Lau R, Samarrai W, et al. The molecular genetic architecture of attention deficit hyperactivity disorder. Mol Psychiatry 2015;20:289-297.

26) Franke B, Neale BM, Faraone SV. Genome-wide association studies in ADHD. Hum Genet 2009;126:13-50.

27) Arcos-Burgos M, Jain M, Acosta MT, Shively S, Stanescu H, Wallis D, et al. A common variant of the latrophilin 3 gene, LPHN3, confers susceptibility to ADHD and predicts effectiveness of stimulant medication. Mol Psychiatry 2010;15:1053-1066.

28) Reif A, Nguyen TT, Weissflog L, Jacob CP, Romanos M, Renner TJ, et al. DIRAS2 is associated with adult ADHD, related traits, and co-morbid disorders. Neuropsychopharmacology 2011;36: 2318-2327.

29) Lesch KP, Merker S, Reif A, Novak M. Dances with black widow spiders: dysregulation of glutamate signalling enters centre stage in ADHD. Eur Neuropsychopharmacol 2013;23:479-491.

30) Salatino-Oliveira A, Genro JP, Polanczyk G, Zeni C, Schmitz M, Kieling C, et al. Cadherin-13 gene is associated with hyperactive/impulsive symptoms in attention/deficit hyperactivity disorder. Am J Med Genet B Neuropsychiatr Genet 2015;168B:162-169.

31) Lesch KP, Selch S, Renner TJ, Jacob C, Nguyen TT, Hahn T, et al. Genome-wide copy number variation analysis in attention-deficit/hyperactivity disorder: association with neuropeptide Y gene dosage in an extended pedigree. Mol Psychiatry 2011;16:491-503.

32) Ramos-Quiroga JA, Nasillo V, Fernández-Aranda F, Casas M. Addressing the lack of studies in attention-deficit/hyperactivity disorder in adults. Expert Rev Neurother 2014;14:553-567.

33) Ramos-Quiroga JA, Sánchez-Mora C, Casas M, Garcia-Martínez I, Bosch R, Nogueira M, et al. Genome-wide copy number variation analysis in adult attention-deficit and hyperactivity disorder. J Psychiatr Res 2014;49:60-67.

34) dela Peña I, Kim HJ, Sohn A, Kim BN, Han DH, Ryu JH, et al. Prefrontal cortical and striatal transcriptional responses to the reinforcing effect of repeated methylphenidate treatment in the spontaneously hypertensive rat, animal model of attention-deficit/hyperactivity disorder (ADHD). Behav Brain Funct 2014;10:17.

35) Barkley RA. Attention-deficit hyperactivity disorder: a handbook for diagnosis and treatment. 3rd ed. New York: Guilford Press;2006. p.704-736.

36) Bush G, Valera EM, Seidman LJ. Functional neuroimaging of attention-deficit/hyperactivity disorder: a review and suggested future directions. Biol Psychiatry 2005;57:1273-1284.

37) Castellanos FX, Margulies DS, Kelly C, Uddin LQ, Ghaffari M, Kirsch A, et al. Cingulate-precuneus interactions: a new locus of dysfunction in adult attention-deficit/hyperactivity disorder. Biol Psychiatry 2008;63:332-337.

38) Ehlis AC, Bähne CG, Jacob CP, Herrmann MJ, Fallgatter AJ. Reduced lateral prefrontal activation in adult patients with attention-deficit/hyperactivity disorder (ADHD) during a working memory task: a functional near-infrared spectroscopy (fNIRS) study. J Psychiatr Res 2008;42:1060-1067.

39) Arnsten AF, Pliszka SR. Catecholamine influences on prefrontal cortical function: relevance to treatment of attention deficit/hyperactivity disorder and related disorders. Pharmacol Biochem Behav 2011;99:211-216. 
40) Kesner RP, Churchwell JC. An analysis of rat prefrontal cortex in mediating executive function. Neurobiol Learn Mem 2011;96: 417-431.

41) Shaw P, Eckstrand K, Sharp W, Blumenthal J, Lerch JP, Greenstein $\mathrm{D}$, et al. Attention-deficit/hyperactivity disorder is characterized by a delay in cortical maturation. Proc Natl Acad Sci U S A 2007;104:19649-19654.

42) Hoogman M, Muetzel R, Guimaraes JP, Shumskaya E, Mennes M, Zwiers MP, et al. Brain imaging of the cortex in ADHD: a coordinated analysis of large-scale clinical and population-based samples. Am J Psychiatry 2019;176:531-542.

43) Zametkin AJ, Nordahl TE, Gross M, King AC, Semple WE, Rumsey J, et al. Cerebral glucose metabolism in adults with hyperactivity of childhood onset. N Engl J Med 1990;323:1361-1366.

44) Spencer TJ, Biederman J, Madras BK, Dougherty DD, Bonab AA, Livni E, et al. Further evidence of dopamine transporter dysregulation in ADHD: a controlled PET imaging study using altropane. Biol Psychiatry 2007;62:1059-1061.

45) Thapar A, Cooper M, Eyre O, Langley K. What have we learnt about the causes of ADHD? J Child Psychol Psychiatry 2013;54: 3-16.

46) Hong SB, Im MH, Kim JW, Park EJ, Shin MS, Kim BN, et al. Environmental lead exposure and attention deficit/hyperactivity disorder symptom domains in a community sample of South Korean school-age children. Environ Health Perspect 2015;123:271276.

47) Kim JI, Kim JW, Lee JM, Yun HJ, Sohn CH, Shin MS, et al. Interaction between DRD2 and lead exposure on the cortical thickness of the frontal lobe in youth with attention-deficit/hyperactivity disorder. Prog Neuropsychopharmacol Biol Psychiatry 2018;82:169-176.

48) Sadock BJ, Sadock VA, Ruiz P. Kaplan and Sadock's synopsis of psychiatry: behavioral sciences/clinical psychiatry. 11th ed. Philadelphia, PA: Wolters Kluwer;2014.

49) American Psychiatric Association. Diagnostic and statistical manual of mental disorder: DSM-IV. Washington, DC: American Psychiatric Press Inc.;1994.

50) American Psychiatric Association. Diagnostic and statistical manual of mental disorders: DSM-5. Arlington, VA: American Psychiatric Publishing;2013

51) Weyandt L, DuPaul G. College students with ADHD: current issues and future directions. New York, NY: Springer;2013.

52) Franke B, Michelini G, Asherson P, Banaschewski T, Bilbow A, Buitelaar JK, et al. Live fast, die young? A review on the developmental trajectories of ADHD across the lifespan. Eur Neuropsychopharmacol 2018;28:1059-1088

53) Adler L, Cohen J. Diagnosis and evaluation of adults with attention-deficit/hyperactivity disorder. Psychiatr Clin North Am 2004:27:187-201.

54) Philipp-Wiegmann F, Retz-Junginger P, Retz W, Rösler M. The intraindividual impact of ADHD on the transition of adulthood to old age. Eur Arch Psychiatry Clin Neurosci 2016;266:367-371.

55) Kooij JJ, Michielsen M, Kruithof H, Bijlenga D. ADHD in old age: a review of the literature and proposal for assessment and treatment. Expert Rev Neurother 2016;16:1371-1381.

56) Dalsgaard S, Østergaard SD, Leckman JF, Mortensen PB, Pedersen MG. Mortality in children, adolescents, and adults with attention deficit hyperactivity disorder: a nationwide cohort study. Lancet 2015;385:2190-2196.

57) London AS, Landes SD. Attention deficit hyperactivity disorder and adult mortality. Prev Med 2016;90:8-10.

58) Guldberg-Kjär T, Johansson B. Old people reporting childhood $\mathrm{AD} / \mathrm{HD}$ symptoms: retrospectively self-rated $\mathrm{AD} / \mathrm{HD}$ symptoms in a population-based Swedish sample aged 65-80. Nord J Psychiatry 2009;63:375-382

59) Giupponi G, Giordano G, Maniscalco I, Erbuto D, Berardelli I,
Conca A, et al. Suicide risk in attention-deficit/hyperactivity disorder. Psychiatr Danub 2018;30:2-10.

60) Stickley A, Tachimori H, Inoue Y, Shinkai T, Yoshimura R, Nakamura J, et al. Attention-deficit/hyperactivity disorder symptoms and suicidal behavior in adult psychiatric outpatients. Psychiatry Clin Neurosci 2018;72:713-722.

61) Polanczyk G, Rohde LA. Epidemiology of attention-deficit/hyperactivity disorder across the lifespan. Curr Opin Psychiatry 2007;20:386-392.

62) Fayyad J, Sampson NA, Hwang I, Adamowski T, Aguilar-Gaxiola S, Al-Hamzawi A, et al. The descriptive epidemiology of DSMIV Adult ADHD in the World Health Organization World Mental Health Surveys. Atten Defic Hyperact Disord 2017;9:47-65.

63) Hwangbo R, Chang H, Hong M, Cho S, Bahn GH. The diagnostic distribution of psychiatric disorders among the population under 19 years old: based on the National Insurance Data. J Korean Acad Child Adolesc Psychiatry 2016;27:139-145.

64) Moffitt TE, Houts R, Asherson P, Belsky DW, Corcoran DL, Hammerle M, et al. Is adult ADHD a childhood-onset neurodevelopmental disorder? Evidence from a four-decade longitudinal cohort study. Am J Psychiatry 2015;172:967-977.

65) Agnew-Blais JC, Polanczyk GV, Danese A, Wertz J, Moffitt TE, Arseneault L. Evaluation of the persistence, remission, and emergence of attention-deficit/hyperactivity disorder in young adulthood. JAMA Psychiatry 2016;73:713-720.

66) Cooper M, Hammerton G, Collishaw S, Langley K, Thapar A, Dalsgaard S, et al. Investigating late-onset ADHD: a population cohort investigation. J Child Psychol Psychiatry 2018;59:11051113.

67) Ramos-Olazagasti MA, Castellanos FX, Mannuzza S, Klein RG. Predicting the adult functional outcomes of boys with ADHD 33 years later. J Am Acad Child Adolesc Psychiatry 2018;57:571582

68) Noh GM, Lee SM, Bahn GH. Social function of adult men with attention-deficit/hyperactivity disorder in the context of military service. Neuropsychiatr Dis Treat 2018;14:3349-3354.

69) Teive HA, Zavala JA, Munhoz RP, Lara DR, Lima P, Palmini A. Attention deficit hyperactivity disorder and the behavior of "Che" Guevara. J Clin Neurosci 2009;16:1136-1138.

70) Fitzgerald M. Adult deficit hyperactivity disorder and other diagnosis. Ir J Psychol Med 2008;25:160.

71) Simon V, Czobor P, Bálint S, Mészáros A, Bitter I. Prevalence and correlates of adult attention-deficit hyperactivity disorder: meta-analysis. Br J Psychiatry 2009;194:204-211.

72) Caye A, Swanson J, Thapar A, Sibley M, Arseneault L, Hechtman L, et al. Life span studies of ADHD-conceptual challenges and predictors of persistence and outcome. Curr Psychiatry Rep 2016; 18:111.

73) Sibley MH, Mitchell JT, Becker SP. Method of adult diagnosis influences estimated persistence of childhood ADHD: a systematic review of longitudinal studies. Lancet Psychiatry 2016;3:11571165.

74) Sibley MH, Swanson JM, Arnold LE, Hechtman LT, Owens EB, Stehli A, et al. Defining ADHD symptom persistence in adulthood: optimizing sensitivity and specificity. J Child Psychol Psychiatry 2017;58:655-662.

75) Ramos-Quiroga JA, Montoya A, Kutzelnigg A, Deberdt W, Sobanski E. Attention deficit hyperactivity disorder in the European adult population: prevalence, disease awareness, and treatment guidelines. Curr Med Res Opin 2013;29:1093-1104.

76) Zalsman G, Shilton T. Adult ADHD: A new disease? Int J Psychiatry Clin Pract 2016;20:70-76.

77) Rigler T, Manor I, Kalansky A, Shorer Z, Noyman I, Sadaka Y. New DSM-5 criteria for ADHD - does it matter? Compr Psychiatry 2016;68:56-59.

78) Barkley RA, Brown TE. Unrecognized attention-deficit/hyperac- 
tivity disorder in adults presenting with other psychiatric disorders. CNS Spectr 2008;13:977-984.

79) Matte B, Anselmi L, Salum GA, Kieling C, Gonçalves H, Menezes A, et al. ADHD in DSM-5: a field trial in a large, representative sample of 18- to 19-year-old adults. Psychol Med 2015;45:361373.

80) Park S, Cho MJ, Chang SM, Jeon HJ, Cho SJ, Kim BS, et al. Prevalence, correlates, and comorbidities of adult ADHD symptoms in Korea: results of the Korean epidemiologic catchment area study. Psychiatry Res 2011;186:378-383.

81) Kwak YS, Jung YE, Kim MD. Prevalence and correlates of attention-deficit hyperactivity disorder symptoms in Korean college students. Neuropsychiatr Dis Treat 2015;11:797-802.

82) Faraone SV, Biederman J, Mick E. The age-dependent decline of attention deficit hyperactivity disorder: a meta-analysis of follow-up studies. Psychol Med 2006;36:159-165.

83) Kooij SJ, Bejerot S, Blackwell A, Caci H, Casas-Brugué M, Carpentier PJ, et al. European consensus statement on diagnosis and treatment of adult ADHD: The European Network Adult ADHD. BMC Psychiatry 2010;10:67.

84) Pingault JB, Viding E, Galéra C, Greven CU, Zheng Y, Plomin R, et al. Genetic and environmental influences on the developmental course of attention-deficit/hyperactivity disorder symptoms from childhood to adolescence. JAMA Psychiatry 2015;72:651658.

85) Biederman J. Attention-deficit/hyperactivity disorder: a selective overview. Biol Psychiatry 2005;57:1215-1220.

86) Genolini C, Pingault JB, Driss T, Côté $S$, Tremblay RE, Vitaro F, et al. KmL3D: a non-parametric algorithm for clustering joint trajectories. Comput Methods Programs Biomed 2013;109:104111.

87) Willcutt EG, Nigg JT, Pennington BF, Solanto MV, Rohde LA, Tannock R, et al. Validity of DSM-IV attention deficit/hyperactivity disorder symptom dimensions and subtypes. J Abnorm Psychol 2012;121:991-1010.

88) Willoughby MT. Developmental course of ADHD symptomatology during the transition from childhood to adolescence: a review with recommendations. J Child Psychol Psychiatry 2003; 44:88-106.

89) Larsson H, Dilshad R, Lichtenstein P, Barker ED. Developmental trajectories of DSM-IV symptoms of attention-deficit/hyperactivity disorder: genetic effects, family risk and associated psychopathology. J Child Psychol Psychiatry 2011;52:954-963.

90) Pingault JB, Côté SM, Vitaro F, Falissard B, Genolini C, Tremblay RE. The developmental course of childhood inattention symptoms uniquely predicts educational attainment: a 16-year longitudinal study. Psychiatry Res 2014;219:707-709.

91) Pingault JB, Tremblay RE, Vitaro F, Carbonneau R, Genolini $C$, Falissard B, et al. Childhood trajectories of inattention and hyperactivity and prediction of educational attainment in early adulthood: a 16-year longitudinal population-based study. Am J Psychiatry 2011;168:1164-1170.

92) Retz W, Stieglitz RD, Corbisiero S, Retz-Junginger P, Rosler M. Emotional dysregulation in adult ADHD: What is the empirical evidence? Expert Rev Neurother 2012;12:1241-1251.

93) Surman CB, Biederman J, Spencer T, Yorks D, Miller CA, Petty CR, et al. Deficient emotional self-regulation and adult attention deficit hyperactivity disorder: a family risk analysis. Am J Psychiatry 2011;168:617-623.

94) Amador-Campos JA, Gómez-Benito J, Ramos-Quiroga JA. The conners' adult ADHD rating scales--short self-report and observer forms: psychometric properties of the Catalan version. J Atten Disord 2014;18:671-679.

95) Christiansen H, Kis B, Hirsch O, Philipsen A, Henneck M, Panczuk A, et al. German validation of the Conners Adult ADHD Rating Scales-self-report (CAARS-S) I: factor structure and nor- mative data. Eur Psychiatry 2011;26:100-107.

96) Kessler RC, Green JG, Adler LA, Barkley RA, Chatterji S, Faraone SV, et al. Structure and diagnosis of adult attention-deficit/ hyperactivity disorder: analysis of expanded symptom criteria from the Adult ADHD Clinical Diagnostic Scale. Arch Gen Psychiatry 2010;67:1168-1178.

97) Marchant BK, Reimherr FW, Robison D, Robison RJ, Wender PH. Psychometric properties of the Wender-Reimherr Adult Attention Deficit Disorder Scale. Psychol Assess 2013;25:942-950.

98) Sagvolden T, Johansen EB, Aase H, Russell VA. A dynamic developmental theory of attention-deficit/hyperactivity disorder (ADHD) predominantly hyperactive/impulsive and combined subtypes. Behav Brain Sci 2005;28:397-419.

99) Sandberg S. The biopsychosocial context of ADHD. Behav Brain Sci 2005;28:441-442.

100) Turgay A, Goodman DW, Asherson P, Lasser RA, Babcock TF, Pucci ML, et al. Lifespan persistence of ADHD: the life transition model and its application. J Clin Psychiatry 2012;73:192-201.

101) Barkley RA, Fischer M, Smallish L, Fletcher K. Young adult outcome of hyperactive children: adaptive functioning in major life activities. J Am Acad Child Adolesc Psychiatry 2006;45:192202.

102) DuPaul GJ, Weyandt LL, O’Dell SM, Varejao M. College students with ADHD: current status and future directions. J Atten Disord 2009;13:234-250.

103) Frazier TW, Youngstrom EA, Glutting JJ, Watkins MW. ADHD and achievement: meta-analysis of the child, adolescent, and adult literatures and a concomitant study with college students. J Learn Disabil 2007;40:49-65.

104) Norwalk K, Norvilitis JM, MacLean MG. ADHD symptomatology and its relationship to factors associated with college adjustment. J Atten Disord 2009;13:251-258.

105) Gray SA, Fettes P, Woltering S, Mawjee K, Tannock R. Symptom manifestation and impairments in college students with ADHD. J Learn Disabil 2016;49:616-630.

106) Harpin VA. The effect of ADHD on the life of an individual, their family, and community from preschool to adult life. Arch Dis Child 2005;90 Suppl 1:i2-7.

107) Gjervan B, Torgersen T, Nordahl HM, Rasmussen K. Functional impairment and occupational outcome in adults with ADHD. J Atten Disord 2012;16:544-552.

108) Halmøy A, Fasmer OB, Gillberg C, Haavik J. Occupational outcome in adult ADHD: impact of symptom profile, comorbid psychiatric problems, and treatment: a cross-sectional study of 414 clinically diagnosed adult ADHD patients. J Atten Disord 2009; 13:175-187.

109) de Graaf R, Kessler RC, Fayyad J, ten Have M, Alonso J, Angermeyer M, et al. The prevalence and effects of adult attention-deficit/hyperactivity disorder (ADHD) on the performance of workers: results from the WHO World Mental Health Survey Initiative. Occup Environ Med 2008;65:835-842.

110) Brook JS, Brook DW, Zhang C, Seltzer N, Finch SJ. Adolescent ADHD and adult physical and mental health, work performance, and financial stress. Pediatrics 2013;131:5-13.

111) Breslin FC, Pole JD. Work injury risk among young people with learning disabilities and attention-deficit/hyperactivity disorder in Canada. Am J Public Health 2009;99:1423-1430.

112) Hodgkins P, Montejano L, Sasané R, Huse D. Risk of injury associated with attention-deficit/hyperactivity disorder in adults enrolled in employer-sponsored health plans: a retrospective analysis. Prim Care Companion CNS Disord 2011;13:PCC.10m01031.

113) Küpper T, Haavik J, Drexler H, Ramos-Quiroga JA, Wermelskirchen D, Prutz C, et al. The negative impact of attention-deficit/hyperactivity disorder on occupational health in adults and adolescents. Int Arch Occup Environ Health 2012;85:837-847.

114) Fruchter E, Marom-Harel H, Fenchel D, Kapra O, Ginat K, Por- 
tuguese S, et al. Functioning of young adults with ADHD in the military. J Atten Disord 2019;23:1470-1474.

115) Lee DY, Lee CS, Park CS, Kim BJ, Cha BS, Lee SJ, et al. Effect of symptoms of adult attention deficit hyperactivity disorder on symptoms of post traumatic stress disorder in Korean conscripts. Psychiatry Investig 2012;9:154-160.

116) Robin AL, Payson E. The impact of ADHD on marriage. ADHD Rep 2002;10:9-14

117) Shaw P, Stringaris A, Nigg J, Leibenluft E. Emotion dysregulation in attention deficit hyperactivity disorder. Am J Psychiatry 2014;171:276-293.

118) Barkley RA, Murphy KR. Deficient emotional self-regulation in adults with ADHD: the relative contributions of emotional impulsiveness and ADHD symptoms to adaptive impairments in major life activities. J ADHD Relat Disord 2010;1:5-28.

119) Skirrow C, Asherson P. Emotional lability, comorbidity and impairment in adults with attention-deficit hyperactivity disorder. $\mathrm{J}$ Affect Disord 2013;147:80-86.

120) Surman CB, Biederman J, Spencer T, Miller CA, McDermott KM, Faraone SV. Understanding deficient emotional self-regulation in adults with attention deficit hyperactivity disorder: a controlled study. Atten Defic Hyperact Disord 2013;5:273-281.

121) Mörstedt B, Corbisiero S, Bitto H, Stieglitz RD. Emotional symptoms and their contribution to functional impairment in adults with attention-deficit/hyperactivity disorder. Atten Defic Hyperact Disord 2016;8:21-33.

122) Minde K, Eakin L, Hechtman L, Ochs E, Bouffard R, Greenfield B, et al. The psychosocial functioning of children and spouses of adults with ADHD. J Child Psychol Psychiatry 2003;44:637-646.

123) Rhee SH, Waldman ID, Hay DA, Levy F. Sex differences in genetic and environmental influences on DSM-III-R attention-deficit/hyperactivity disorder. J Abnorm Psychol 1999;108:24-41.

124) Canu WH, Carlson CL. Rejection sensitivity and social outcomes of young adult men with ADHD. J Atten Disord 2007;10: 261-275.

125) Eakin L, Minde K, Hechtman L, Ochs E, Krane E, Bouffard R, et al. The marital and family functioning of adults with ADHD and their spouses. J Atten Disord 2004;8:1-10.

126) Barkley RA, Cox D. A review of driving risks and impairments associated with attention-deficit/hyperactivity disorder and the effects of stimulant medication on driving performance. J Safety Res 2007;38:113-128.

127) Rosenbloom T, Wultz B. Thirty-day self-reported risky driving behaviors of ADHD and non-ADHD drivers. Accid Anal Prev 2011;43:128-133.

128) Swensen A, Birnbaum HG, Ben Hamadi R, Greenberg P, Cremieux PY, Secnik K. Incidence and costs of accidents among attention-deficit/hyperactivity disorder patients. J Adolesc Health 2004:35:346.e1-346.e9

129) Flory K, Molina BS, Pelham WE Jr, Gnagy E, Smith B. Childhood ADHD predicts risky sexual behavior in young adulthood. J Clin Child Adolesc Psychol 2006;35:571-577.

130) Gudjonsson GH, Sigurdsson JF, Sigfusdottir ID, Young S. An epidemiological study of ADHD symptoms among young persons and the relationship with cigarette smoking, alcohol consumption and illicit drug use. J Child Psychol Psychiatry 2012; 53:304-312.

131) Caye A, Rocha TB, Anselmi L, Murray J, Menezes AM, Barros FC, et al. Attention-deficit/hyperactivity disorder trajectories from childhood to young adulthood: evidence from a birth cohort supporting a late-onset syndrome. JAMA Psychiatry 2016; 73:705-712

132) Mannuzza S, Klein RG, Moulton JL 3rd. Lifetime criminality among boys with attention deficit hyperactivity disorder: a prospective follow-up study into adulthood using official arrest records. Psychiatry Res 2008;160:237-246.
133) Knecht C, de Alvaro R, Martinez-Raga J, Balanza-Martinez V. Attention-deficit hyperactivity disorder (ADHD), substance use disorders, and criminality: a difficult problem with complex solutions. Int J Adolesc Med Health 2015;27:163-175.

134) Cahill BS, Coolidge FL, Segal DL, Klebe KJ, Marle PD, Overmann KA. Prevalence of ADHD and its subtypes in male and female adult prison inmates. Behav Sci Law 2012;30:154-166.

135) Galland D, Tisserant I, Notardonato L. ["Attention deficit hyperactivity disorder in forensic psychiatry: a review”]. Encephale 2017;43:268-272.

136) Wasserstein J. Diagnostic issues for adolescents and adults with ADHD. J Clin Psychol 2005;61:535-547.

137) Murphy P, Schachar R. Use of self-ratings in the assessment of symptoms of attention deficit hyperactivity disorder in adults. Am J Psychiatry 2000;157:1156-1159.

138) Zucker M, Morris MK, Ingram SM, Morris RD, Bakeman R. Concordance of self- and informant ratings of adults' current and childhood attention-deficit/hyperactivity disorder symptoms. Psychol Assess 2002;14:379-389.

139) Brown TE. Attention-deficit disorders and comorbidities in children, adolescents, and adults. Washington, NY: American Psyciatric Press, Inc.;2000.

140) Canela C, Buadze A, Dube A, Eich D, Liebrenz M. Skills and compensation strategies in adult ADHD - A qualitative study. PLoS One 2017;12:e0184964.

141) Adler LA. Clinical presentations of adult patients with ADHD. J Clin Psychiatry 2004;65 Suppl 3:8-11.

142) Mao AR, Findling RL. Comorbidities in adult attention-deficit/ hyperactivity disorder: a practical guide to diagnosis in primary care. Postgrad Med 2014;126:42-51.

143) Conners CK, Jett JL. Attention deficit hyperactivity disorder: The latest assessment and treatment strategies. Kansas City, MO: Compact Clinicals;1999.

144) Francks C, Fisher SE, Marlow AJ, MacPhie IL, Taylor KE, Richardson AJ, et al. Familial and genetic effects on motor coordination, laterality, and reading-related cognition. Am J Psychiatry 2003;160:1970-1977.

145) Ronald A, Simonoff E, Kuntsi J, Asherson P, Plomin R. Evidence for overlapping genetic influences on autistic and ADHD behaviours in a community twin sample. J Child Psychol Psychiatry 2008;49:535-542.

146) Willcutt EG, Pennington BF, Olson RK, DeFries JC. Understanding comorbidity: a twin study of reading disability and attentiondeficit/hyperactivity disorder. Am J Med Genet B Neuropsychiatr Genet 2007;144B:709-714.

147) Kessler RC, Adler L, Ames M, Demler O, Faraone S, Hiripi E, et al. The World Health Organization Adult ADHD Self-Report Scale (ASRS): a short screening scale for use in the general population. Psychol Med 2005;35:245-256.

148) Heo S, Kim JH, Joung YS, Lee WI, Kim JJ, Sohn SH, et al. Clinical utility of the Korean version of the WHO Adult AttentionDeficit/Hyperactivity Disorder Self-Report Scale Screener. Psychiatry Investig 2018;15:325-329.

149) Ustun B, Adler LA, Rudin C, Faraone SV, Spencer TJ, Berglund P, et al. The World Health Organization Adult Attention-Deficit/ Hyperactivity Disorder Self-Report Screening Scale for DSM-5. JAMA Psychiatry 2017;74:520-527.

150) Conners CK, Erhardt D, Sparrow EP. Conners' adult ADHD rating scales (CAARS): technical manual. North Tonawanda, NY: Multi-Health Systems Inc.;1999.

151) Rossini ED, O’Connor MA. Retrospective self-reported symptoms of attention-deficit hyperactivity disorder: reliability of the Wender Utah Rating Scale. Psychol Rep 1995;77(3 Pt 1):751-754.

152) Goldstein S, Naglieri JA. Brown Attention-Deficit-Disorder Scales for adolescents and adults. In: Encyclopedia of child behavior and development. Boston, MA: Springer;2011. p.303-303. 
153) Barkley RA, Murphy KR. Attention-deficit hyperactivity disorder: a clinical workbook. 3rd ed. New York, NY: The Guilford Press;2006.

154) Young S. The YAQ-S and YAQ-I: the development of self and informant questionnaires reporting on current adult ADHD symptomatology, comorbid and associated problems. Pers Individ Dif 2004;36:1211-1223

155) Hong M, Lee YS, Kim B, Joung YS, Yoo HK, Kim E, et al. Clinical utility and cut-off scores of the Korean Adult Attention-Deficit/Hyperactivity Disorder Rating Scale. J Korean Acad Child Adolesc Psychiatry 2019;30:116-120.

156) Barkley RA, Murphy KR. The nature of executive function (EF) deficits in daily life activities in adults with ADHD and their relationship to performance on EF tests. J Psychopathol Behav Assess 2011;33:137-158.

157) Lee H, Yang M, Lee E-h, Joung Y-S, Hwang S-t, Hong S-H, et al. Reliability and validity of the Korean version of Barkley Deficits in Executive Functioning Scale (K-BDEFS). Korean J Clin Psychol 2016;35:519-539.

158) Kooij J. Diagnostic instrument. In: Adult ADHD: diagnostic assessment and treatment. 3rd ed. London: Springer-Verlag;2013. p.97-98.

159) Epstein JN, Johnson DE, Conners CK. Conners' Adult ADHD Diagnostic Interview for DSM-IVTM (CAADID ${ }^{\mathrm{TM}}$ ). North Tonawanda, NY: Multi-Health Systems Inc.;2001.

160) Huh HN, Kang SH, Hwang SY, Yoo HK. Developmental trajectories of attention in normal Korean population. J Korean Acad Child Adolesc Psychiatry 2019;30:66-73.

161) Holst Y, Thorell LB. Neuropsychological functioning in adults with ADHD and adults with other psychiatric disorders. J Atten Disord 2017;21:137-148.

162) Mostert JC, Onnink AMH, Klein M, Dammers J, Harneit A, Schulten T, et al. Cognitive heterogeneity in adult attention deficit/hyperactivity disorder: a systematic analysis of neuropsychological measurements. Eur Neuropsychopharmacol 2015;25: 2062-2074.

163) Skodzik T, Holling H, Pedersen A. Long-term memory performance in adult ADHD. J Atten Disord 2017;21:267-283.

164) Weyandt LL, Oster DR, Gudmundsdottir BG, DuPaul GJ, Anastopoulos AD. Neuropsychological functioning in college students with and without ADHD. Neuropsychology 2017;31:160172.

165) Yoo H, Lee J, Kang SH, Park EH, Jung J, Kim BN, et al. Standardization of the comprehensive attention test for the Korean children and adolescents. J Korean Acad Child Adolesc Psychiatry 2009;20:68-75.

166) Kooij JJ, Burger H, Boonstra AM, Van der Linden PD, Kalma LE, Buitelaar JK. Efficacy and safety of methylphenidate in 45 adults with attention-deficit/hyperactivity disorder. A randomized placebo-controlled double-blind cross-over trial. Psychol Med 2004;34:973-982.

167) Sobanski E. Psychiatric comorbidity in adults with attention-deficit/hyperactivity disorder (ADHD). Eur Arch Psychiatry Clin Neurosci 2006;256 Suppl 1:i26-i31.

168) Katzman MA, Bilkey TS, Chokka PR, Fallu A, Klassen LJ. Adult ADHD and comorbid disorders: clinical implications of a dimensional approach. BMC Psychiatry 2017;17:302.

169) Miesch M, Deister A. [Attention-deficit/hyperactivity disorder (ADHD) in adult psychiatry: data on 12-month prevalence, risk factors and comorbidity]. Fortschr Neurol Psychiatr 2019;87:3238.

170) Fatséas M, Hurmic H, Serre F, Debrabant R, Daulouède JP, Denis $\mathbf{C}$, et al. Addiction severity pattern associated with adult and childhood Attention Deficit Hyperactivity Disorder (ADHD) in patients with addictions. Psychiatry Res 2016;246:656-662.

171) Panagiotidi M. Problematic video game play and ADHD traits in an adult population. Cyberpsychol Behav Soc Netw 2017;20: 292-295.

172) Wang BQ, Yao NQ, Zhou X, Liu J, Lv ZT. The association between attention deficit/hyperactivity disorder and internet addiction: a systematic review and meta-analysis. BMC Psychiatry 2017; 17:260.

173) Gibbins C, Weiss M. Clinical recommendations in current practice guidelines for diagnosis and treatment of ADHD in adults. Curr Psychiatry Rep 2007;9:420-426.

174) Kessler RC, Adler L, Barkley R, Biederman J, Conners CK, Demler $\mathbf{O}$, et al. The prevalence and correlates of adult ADHD in the United States: results from the National Comorbidity Survey Replication. Am J Psychiatry 2006;163:716-723.

175) Klassen LJ, Katzman MA, Chokka P. Adult ADHD and its comorbidities, with a focus on bipolar disorder. J Affect Disord 2010;124:1-8.

176) Piñeiro-Dieguez B, Balanzá-Martínez V, García-García P, SolerLópez B; CAT Study Group. Psychiatric comorbidity at the time of diagnosis in adults with ADHD: The CAT Study. J Atten Disord 2016;20:1066-1075.

177) Elkins RM, Carpenter AL, Pincus DB, Comer JS. Inattention symptoms and the diagnosis of comorbid attention-deficit/hyperactivity disorder among youth with generalized anxiety disorder. J Anxiety Disord 2014;28:754-760.

178) Reimherr FW, Marchant BK, Gift TE, Steans TA. ADHD and anxiety: clinical significance and treatment implications. Curr Psychiatry Rep 2017;19:109.

179) Milberger S, Biederman J, Faraone SV, Murphy J, Tsuang MT. Attention deficit hyperactivity disorder and comorbid disorders: issues of overlapping symptoms. Am J Psychiatry 1995;152:17931799.

180) Ramsay JR, Rostain AL. Issues in ADHD in adults. The ADHD Report 2006;14:5-8.

181) Ramsay JR. What else could it be if it is NOT adult ADHD? [cited 2019 July 15]. Available from URL: https://adhdinadults.com/ what-else-could-it-be-if-it-is-not-adult-adhd/.

182) Moukhtarian TR, Mintah RS, Moran P, Asherson P. Emotion dysregulation in attention-deficit/hyperactivity disorder and borderline personality disorder. Borderline Personal Disord Emot Dysregul 2018;5:9.

183) Asherson P, Young AH, Eich-Höchli D, Moran P, Porsdal V, Deberdt W. Differential diagnosis, comorbidity, and treatment of attention-deficit/hyperactivity disorder in relation to bipolar disorder or borderline personality disorder in adults. Curr Med Res Opin 2014;30:1657-1672.

184) Matthies SD, Philipsen A. Common ground in Attention Deficit Hyperactivity Disorder (ADHD) and Borderline Personality Disorder (BPD)-review of recent findings. Borderline Personal Disord Emot Dysregul 2014;1:3.

185) Witt O, Brücher K, Biegel G, Petermann F, Schmidt S. [Adult ADHD versus borderline personality disorder: criteria for differential diagnosis]. Fortschr Neurol Psychiatr 2014;82:337-345.

186) D’Amelio R, Retz W, Philipsen A, Rösler M. Psychoedukation und Coaching ADHS im Erwachsenenalter: Manual zur Leitung von Patienten- und Angehörigengruppen. Munich: Urban \& Fischer;2008.

187) National Collaborating Centre for Mental Health. Attention deficit hyperactivity disorder: diagnosis and management of ADHD in children, young people and adults (NICE Clinical Guidelines, No. 72). Leicester: THe British Psychological Society \& The Royal College of Psychiatrists;2009.

188) Bolea-Alamañac B, Nutt DJ, Adamou M, Asherson P, Bazire S, Coghill D, et al. Evidence-based guidelines for the pharmacological management of attention deficit hyperactivity disorder: update on recommendations from the British Association for Psychopharmacology. J Psychopharmacol 2014;28:179-203. 
189) Volkow ND, Swanson JM. Clinical practice: adult attention deficit-hyperactivity disorder. N Engl J Med 2013;369:1935-1944.

190) Kooij JJS, Bijlenga D, Salerno L, Jaeschke R, Bitter I, Balázs J, et al. Updated European Consensus Statement on diagnosis and treatment of adult ADHD. Eur Psychiatry 2019;56:14-34.

191) Faraone SV, Glatt SJ. A comparison of the efficacy of medications for adult attention-deficit/hyperactivity disorder using meta-analysis of effect sizes. J Clin Psychiatry 2010;71:754-763.

192) Banaschewski T, Coghill D, Santosh P, Zuddas A, Asherson P, Buitelaar J, et al. Long-acting medications for the hyperkinetic disorders. A systematic review and European treatment guideline. Eur Child Adolesc Psychiatry 2006;15:476-495.

193) Philipsen A, Jans T, Graf E, Matthies S, Borel P, Colla M, et al. Effects of group psychotherapy, individual counseling, methylphenidate, and placebo in the treatment of adult attention-deficit/ hyperactivity disorder: a randomized clinical trial. JAMA Psychiatry 2015;72:1199-1210.

194) Chang Z, D’Onofrio BM, Quinn PD, Lichtenstein P, Larsson H. Medication for attention-deficit/hyperactivity disorder and risk for depression: a nationwide longitudinal cohort study. Biol Psychiatry 2016;80:916-922.

195) Chen Q, Sjölander A, Runeson B, D'Onofrio BM, Lichtenstein P, Larsson $\mathrm{H}$. Drug treatment for attention-deficit/hyperactivity disorder and suicidal behaviour: register based study. BMJ 2014; 348:g3769.

196) Chang Z, Lichtenstein P, Halldner L, D'Onofrio B, Serlachius E, Fazel S, et al. Stimulant ADHD medication and risk for substance abuse. J Child Psychol Psychiatry 2014;55:878-885.

197) Chang Z, Lichtenstein P, D'Onofrio BM, Sjölander A, Larsson H. Serious transport accidents in adults with attention-deficit/hyperactivity disorder and the effect of medication: a populationbased study. JAMA Psychiatry 2014;71:319-325.

198) Lichtenstein P, Larsson H. Medication for attention deficit-hyperactivity disorder and criminality. N Engl J Med 2013;368:776.

199) Sharman J, Pennick M. Lisdexamfetamine prodrug activation by peptidase-mediated hydrolysis in the cytosol of red blood cells. Neuropsychiatr Dis Treat 2014;10:2275-2280.

200) Setyawan J, Hodgkins P, Guérin A, Gauthier G, Cloutier M, Wu EQ, et al. Comparing treatment adherence of lisdexamfetamine and other medications for the treatment of attention deficit/hyperactivity disorder: a retrospective analysis. J Med Econ 2013; 16:962-975

201) Adler LA, Goodman DW, Kollins SH, Weisler RH, Krishnan S, Zhang Y, et al. Double-blind, placebo-controlled study of the efficacy and safety of lisdexamfetamine dimesylate in adults with attention-deficit/hyperactivity disorder. J Clin Psychiatry 2008; 69:1364-1373

202) Wigal T, Brams M, Gasior M, Gao J, Squires L, Giblin J; 316 Study Group. Randomized, double-blind, placebo-controlled, crossover study of the efficacy and safety of lisdexamfetamine dimesylate in adults with attention-deficit/hyperactivity disorder: novel findings using a simulated adult workplace environment design. Behav Brain Funct 2010;6:34.

203) Dupaul GJ, Weyandt LL, Rossi JS, Vilardo BA, O’Dell SM, Carson KM, et al. Double-blind, placebo-controlled, crossover study of the efficacy and safety of lisdexamfetamine dimesylate in college students with ADHD. J Atten Disord 2012;16:202-220.

204) Maneeton N, Maneeton B, Suttajit S, Reungyos J, Srisurapanont M, Martin SD. Exploratory meta-analysis on lisdexamfetamine versus placebo in adult ADHD. Drug Des Devel Ther 2014;8: 1685-1693.

205) Coghill DR, Caballero B, Sorooshian S, Civil R. A systematic review of the safety of lisdexamfetamine dimesylate. CNS Drugs 2014;28:497-511.

206) Adler LA, Dirks B, Deas PF, Raychaudhuri A, Dauphin MR, Lasser RA, et al. Lisdexamfetamine dimesylate in adults with at- tention-deficit/ hyperactivity disorder who report clinically significant impairment in executive function: results from a randomized, double-blind, placebo-controlled study. J Clin Psychiatry 2013;74:694-702.

207) Castells X, Ramos-Quiroga JA, Rigau D, Bosch R, Nogueira M, Vidal X, et al. Efficacy of methylphenidate for adults with attention-deficit hyperactivity disorder: a meta-regression analysis. CNS Drugs 2011;25:157-169.

208) Epstein T, Patsopoulos NA, Weiser M. Immediate-release methylphenidate for attention deficit hyperactivity disorder (ADHD) in adults. Cochrane Database Syst Rev 2014:9:CD005041.

209) Martinez-Raga J, Knecht C, Szerman N, Martinez MI. Risk of serious cardiovascular problems with medications for attentiondeficit hyperactivity disorder. CNS Drugs 2013;27:15-30.

210) Coghill D, Banaschewski T, Zuddas A, Pelaz A, Gagliano A, Doepfner M. Long-acting methylphenidate formulations in the treatment of attention-deficit/hyperactivity disorder: a systematic review of head-to-head studies. BMC Psychiatry 2013;13:237.

211) Mick E, McManus DD, Goldberg RJ. Meta-analysis of increased heart rate and blood pressure associated with CNS stimulant treatment of ADHD in adults. Eur Neuropsychopharmacol 2013; 23:534-541.

212) Westover AN, Halm EA. Do prescription stimulants increase the risk of adverse cardiovascular events?: A systematic review. BMC Cardiovasc Disord 2012;12:41.

213) Habel LA, Cooper WO, Sox CM, Chan KA, Fireman BH, Arbogast PG, et al. ADHD medications and risk of serious cardiovascular events in young and middle-aged adults. JAMA 2011; 306:2673-2683.

214) Schelleman H, Bilker WB, Kimmel SE, Daniel GW, Newcomb C, Guevara JP, et al. Methylphenidate and risk of serious cardiovascular events in adults. Am J Psychiatry 2012;169:178-185.

215) Shin JY, Roughead EE, Park BJ, Pratt NL. Cardiovascular safety of methylphenidate among children and young people with attention-deficit/hyperactivity disorder (ADHD): nationwide self controlled case series study. BMJ 2016;353:i2550.

216) Cunill R, Castells X, Tobias A, Capellà D. Atomoxetine for attention deficit hyperactivity disorder in the adulthood: a meta-analysis and meta-regression. Pharmacoepidemiol Drug Saf 2013; 22:961-969.

217) Adler LA, Liebowitz M, Kronenberger W, Qiao M, Rubin R, Hollandbeck M, et al. Atomoxetine treatment in adults with attention-deficit/hyperactivity disorder and comorbid social anxiety disorder. Depress Anxiety 2009;26:212-221.

218) Atomoxetine ADHD and Comorbid MDD Study Group, Bangs ME, Emslie GJ, Spencer TJ, Ramsey JL, Carlson C, Bartky EJ, et al. Efficacy and safety of atomoxetine in adolescents with attention-deficit/hyperactivity disorder and major depression. J Child Adolesc Psychopharmacol 2007;17:407-420.

219) Medori R, Ramos-Quiroga JA, Casas M, Kooij JJ, Niemelä A, Trott GE, et al. A randomized, placebo-controlled trial of three fixed dosages of prolonged-release OROS methylphenidate in adults with attention-deficit/hyperactivity disorder. Biol Psychiatry 2008;63:981-989.

220) Vaughan B, Fegert J, Kratochvil CJ. Update on atomoxetine in the treatment of attention-deficit/hyperactivity disorder. Expert Opin Pharmacother 2009;10:669-676.

221) Maneeton N, Maneeton B, Intaprasert S, Woottiluk P. A systematic review of randomized controlled trials of bupropion versus methylphenidate in the treatment of attention-deficit/hyperactivity disorder. Neuropsychiatr Dis Treat 2014;10:1439-1449.

222) Hamedi M, Mohammdi M, Ghaleiha A, Keshavarzi Z, Jafarnia M, Keramatfar R, et al. Bupropion in adults with attention-deficit/hyperactivity disorder: a randomized, double-blind study. Acta Med Iran 2014;52:675-680.

223) Posey DJ, McDougle CJ. Guanfacine and guanfacine extended 
release: treatment for ADHD and related disorders. CNS Drug Rev 2007;13:465-474

224) Huss M, Chen W, Ludolph AG. Guanfacine extended release: a new pharmacological treatment option in Europe. Clin Drug Investig 2016;36:1-25.

225) Butterfield ME, Saal J, Young B, Young JL. Supplementary guanfacine hydrochloride as a treatment of attention deficit hyperactivity disorder in adults: a double blind, placebo-controlled study. Psychiatry Res 2016;236:136-141.

226) Kollins SH, Jain R, Brams M, Segal S, Findling RL, Wigal SB, et al. Clonidine extended-release tablets as add-on therapy to psychostimulants in children and adolescents with ADHD. Pediatrics 2011;127:e1406-e1413.

227) Jain R, Segal S, Kollins SH, Khayrallah M. Clonidine extendedrelease tablets for pediatric patients with attention-deficit/hyperactivity disorder. J Am Acad Child Adolesc Psychiatry 2011;50: 171-179.

228) Palumbo DR, Sallee FR, Pelham WE Jr, Bukstein OG, Daviss WB, MCDERMOTT MP; CAT STUDY TEAM. Clonidine for attention-deficit/hyperactivity disorder: I. Efficacy and tolerability outcomes. J Am Acad Child Adolesc Psychiatry 2008;47:180188.

229) Hazell PL, Stuart JE. A randomized controlled trial of clonidine added to psychostimulant medication for hyperactive and aggressive children. J Am Acad Child Adolesc Psychiatry 2003; 42:886-894.

230) Otasowie J, Castells X, Ehimare UP, Smith CH. Tricyclic antidepressants for attention deficit hyperactivity disorder (ADHD) in children and adolescents. Cochrane Database Syst Rev 2014;9: CD006997.

231) Prince JB, Wilens TE, Biederman J, Spencer TJ, Millstein R, Polisner DA, et al. A controlled study of nortriptyline in children and adolescents with attention deficit hyperactivity disorder. J Child Adolesc Psychopharmacol 2000;10:193-204.

232) Weiss M, Hechtman L; Adult ADHD Research Group. A randomized double-blind trial of paroxetine and/or dextroamphetamine and problem-focused therapy for attention-deficit/hyperactivity disorder in adults. J Clin Psychiatry 2006;67:611-619.
233) Arnold VK, Feifel D, Earl CQ, Yang R, Adler LA. A 9-week, randomized, double-blind, placebo-controlled, parallel-group, dosefinding study to evaluate the efficacy and safety of modafinil as treatment for adults with ADHD. J Atten Disord 2014;18:133-144.

234) Riahi F, Tehrani-Doost M, Shahrivar Z, Alaghband-Rad J. Efficacy of reboxetine in adults with attention-deficit/hyperactivity disorder: a randomized, placebo-controlled clinical trial. Hum Psychopharmacol 2010;25:570-576.

235) Ghanizadeh A. A systematic review of reboxetine for treating patients with attention deficit hyperactivity disorder. Nord J Psychiatry 2015;69:241-248.

236) Seixas M, Weiss M, Müller U. Systematic review of national and international guidelines on attention-deficit hyperactivity disorder. J Psychopharmacol 2012;26:753-765

237) Arnold LE, Hodgkins P, Caci H, Kahle J, Young S. Effect of treatment modality on long-term outcomes in attention-deficit/hyperactivity disorder: a systematic review. PLoS One 2015;10:e0116407.

238) Philipsen A. Psychotherapy in adult attention deficit hyperactivity disorder: implications for treatment and research. Expert Rev Neurother 2012;12:1217-1225.

239) Mongia M, Hechtman L. Cognitive behavior therapy for adults with attention-deficit/hyperactivity disorder: a review of recent randomized controlled trials. Curr Psychiatry Rep 2012;14:561-567.

240) Hirvikoski T, Waaler E, Alfredsson J, Pihlgren C, Holmström A, Johnson A, et al. Reduced ADHD symptoms in adults with ADHD after structured skills training group: results from a randomized controlled trial. Behav Res Ther 2011;49:175-185.

241) Young S, Emilsson B, Sigurdsson JF, Khondoker M, PhilippWiegmann F, Baldursson G, et al. A randomized controlled trial reporting functional outcomes of cognitive-behavioural therapy in medication-treated adults with ADHD and comorbid psychopathology. Eur Arch Psychiatry Clin Neurosci 2017;267:267-276.

242) Jensen CM, Amdisen BL, Jørgensen KJ, Arnfred SM. Cognitive behavioural therapy for ADHD in adults: systematic review and meta-analyses. Atten Defic Hyperact Disord 2016;8:3-11.

243) Weiss M, Safren SA, Solanto MV, Hechtman L, Rostain AL, Ramsay JR, et al. Research forum on psychological treatment of adults with ADHD. J Atten Disord 2008;11:642-651. 